\title{
COMPARATIVE EFFECT OF METHALONIC EXTRACT OF SYRIAN FENUGREEK AND NIGELLA SATIVA SEEDS ON SOME BIOCHEMICAL PARAMETERS IN MALE DIABETIC RABBITS
}

\author{
S. HOOR and A. ALABBD \\ Department of Physiology Veterinary Faculty, Hama University, Syria
}

Email: Email: hor.zkrya@gmail.com

Assiut University web-site: www.aun.edu.eg

\section{ABSTRACT}

Received at: 12/8/2015

Accepted: 9/9/2015
Present study investigated the effect of methanolic extracts of Fenugreek and Nigella Sativa seeds on blood glucose, total cholesterol and triglyceride, LDL, HDL levels in alloxan diabetic rabbits. The experiment was carried out on 42 of Male rabbits divided into7 groups 6 animals of each: -The first group was kept as normal control. - The second group was given orally the methanolic extract of and Nigella Sativa seeds $1 / 10 \mathrm{LD}_{50}$. -The third group was given orally the methanolic extract of Nigella Sativa seeds $1 / 5 \mathrm{LD}_{50}$. - The forth group was given orally the methanolic extract of Fenugreek seeds $1 / 10 \mathrm{LD}_{50}$. - The fifth group was given orally the methanolic extract of Fenugreek seeds $1 / 10 \mathrm{LD}_{50}$. - The six group was rendered diabetic and treated with insulin. - The seven group was diabetic by intraperitoneal injection of alloxan $(150 \mathrm{mg} / \mathrm{kg}$ b.wt.) and left without treatment. Blood samples were collected at 1,20,40,60 days for determination of glucose, total cholesterol, triglyceride, LDL and HDL levels. The obtained results showed that oral administration of methanolic extracts of methanolic extracts of Fenugreek and Nigella Sativa seeds induced significantly $(\mathrm{p}<0.05)$ decreased blood glucose, total cholesterol, triglyceride and LDL in all remediation experiment groups Especially (third, fifth groups) comparative to the diabetic control group, Methanolic extracts of Fenugreek and Nigella Sativa seeds induced significantly $(\mathrm{p}<0.05)$ increase in HDL in all remediation experiment groups especially (third and fifth groups) in comparative to the diabetic control group.

Key words: Nigella sativa, Fenugreek, Biochemical Parameters.

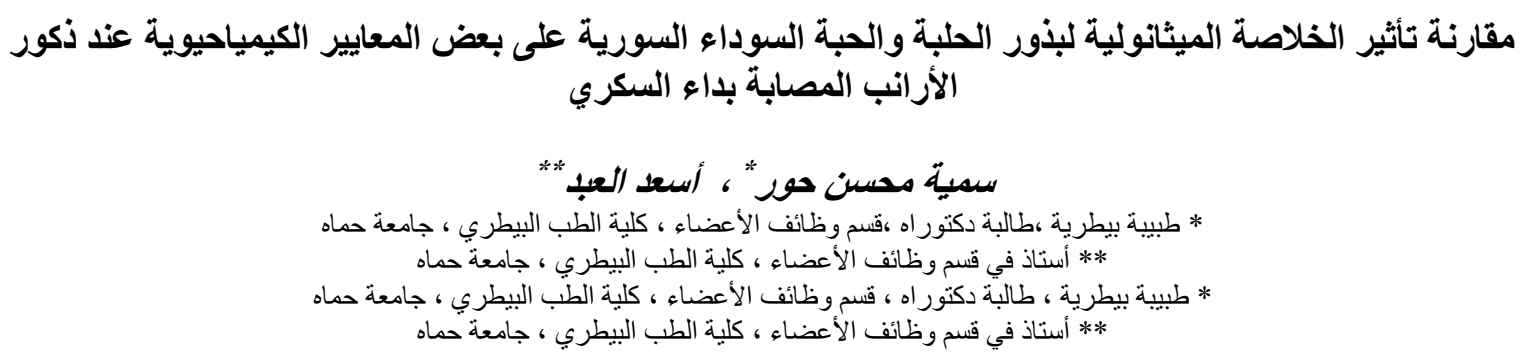




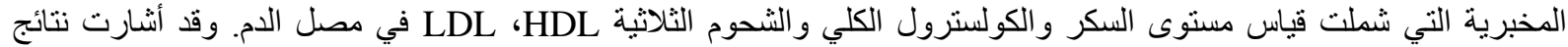

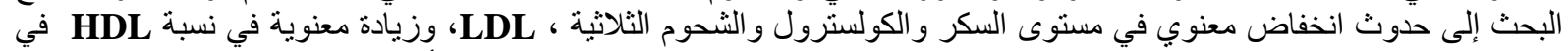

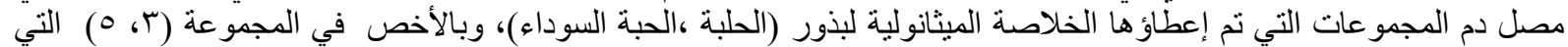

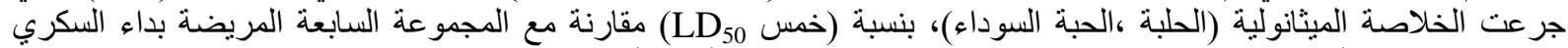
المحدث بو اسطة الألوكسان و غير المعالجة وكان هذا الانخفاض مقارب التأثير الأنسولين.

الكلمات المفتاحية : الحبة السوداء ، الحلبة ،المعايير الكبيمباحبوية

\section{INTRODUCTION}

\section{المقدمسة}

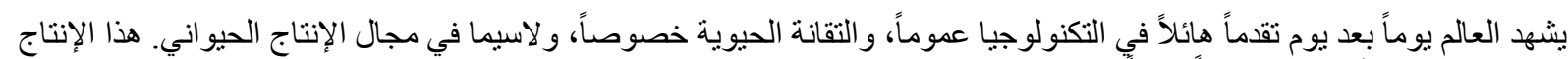

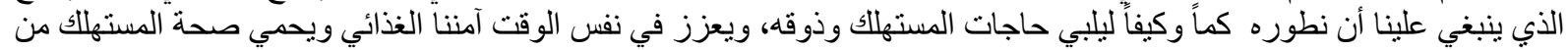
احنمالات.

تنتمي الحبة السوداء إلى المملكة النباتية ، وأسمها العلمي: Nigella Sativa) أما عائلتها فهي في العائلة الحوذانية

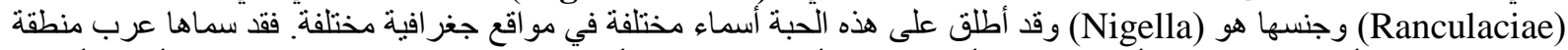

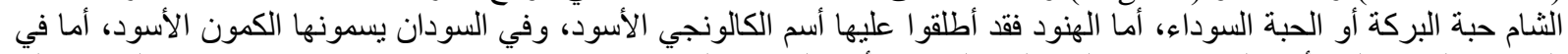

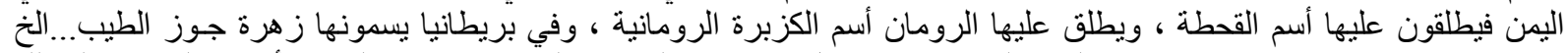

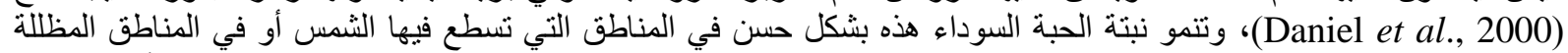

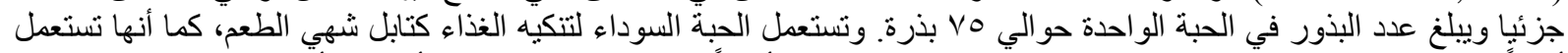

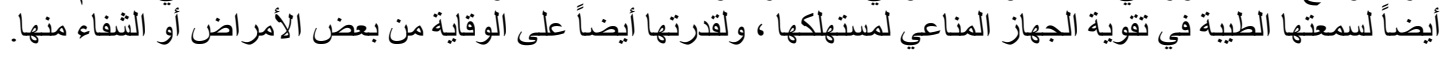

تعتبر الحلبة: (Fenugreek) من النباتات الرعوية لإنشار ها في مناطق متعددة من سوريا والعراق ومصر وتتركز أهميتها الطبية في البذور والأوراق.

وتنتمي إلى عائلة البقوليات ويوجد نوعان من بذور الحلبة وهي بذور الحلبة (Usher 1984)، (Townsnd and Guest., 1980)

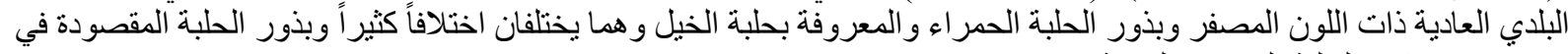
در استتا هي بذور الحلبة الصفراء العادية.

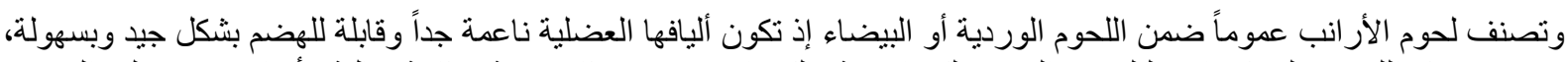

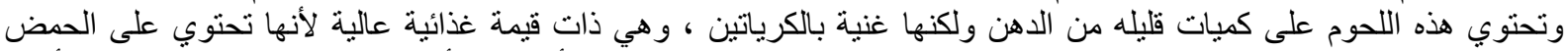

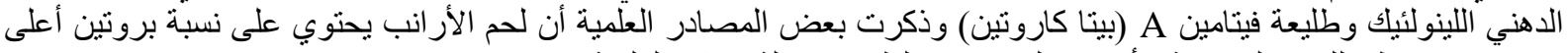
من بروتين معظم اللحوم الحيو انية الأخرى ولحم بعض الطين الطيور (مجلة سافكو العلمية 2006).

تم تحديد الجرعة نصف المميتة في تجربتنا عن طريق التجريع الفموي: Dtermination of lethal medium dos( $\left.\mathbf{L D}_{\mathbf{5 0}}\right)$-orally

تم تحديد الجرعة نصف المميتة لبذور الحبة السوداء عن طريق التجريع الفموي حسب ماورد في (Amein and Attia , 2008) وهي بحدود 1000ملغ/كغ. فيد فيكون:

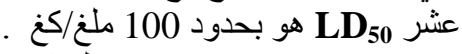
خمس LD

وقد تم تحديد الجر عة نصف المميتة لبذور الحلبة عن طريق التجريع الفموي حسب مـاورد في (كليمـان سعد 2009) و هي بحدود 6500 ملغ/كغ أي 6500 جز هُ في في المليون. عشر خمس Lis

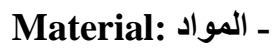

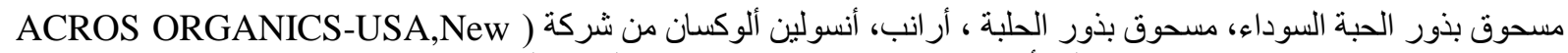

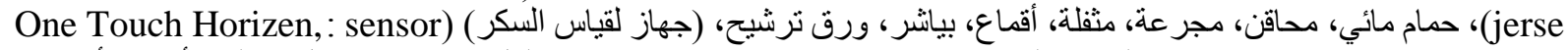

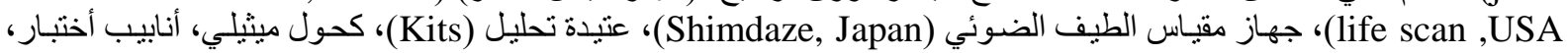
ميزان الكتروني حساس.

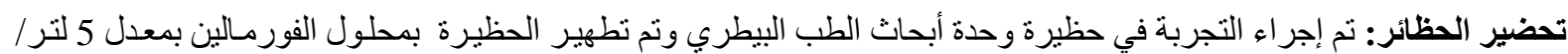

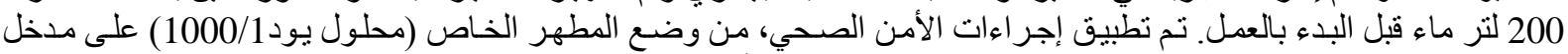
الحظيرة، والتنظيف و التطهير اليومي و المتابعة المستمرة على مدار الألى الأربع و العشرين ساعة. 


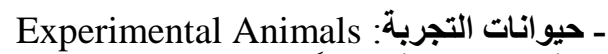

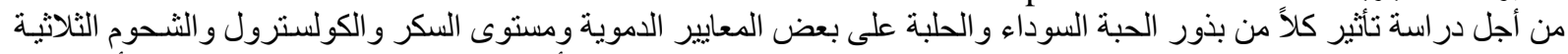

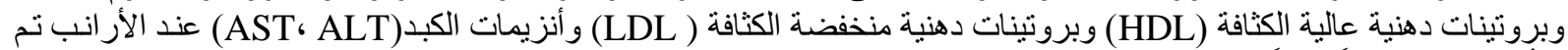

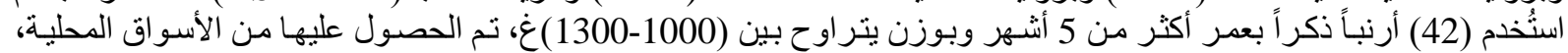

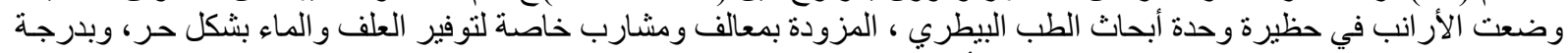

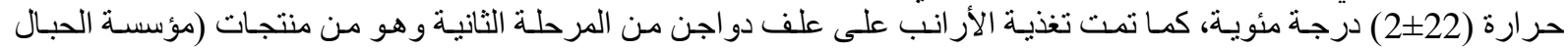

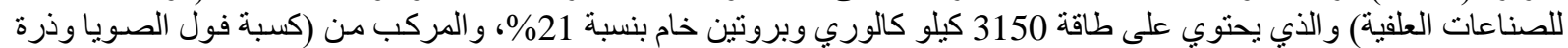

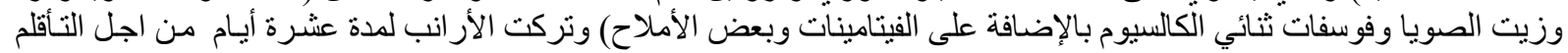

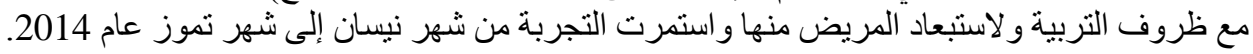

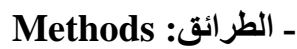 \\ تحضير الخلاصة الميثانولية لبذور الحبة السوداء:}

Preparation of methanolic extract of Nigella sativa seed اعتمدت الطريقة الموصوفة من قبل (Deshmuk and Borle., 1975) في تحضير الخلاصة الميثانولية لبذور الحبة السوداء وذلك

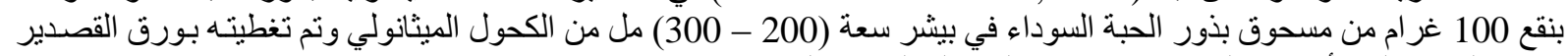
وحفظ المنقو ع لمدة أسبوع بالثلاجة مع مر اعاة التحريك المستمر لهاء له.

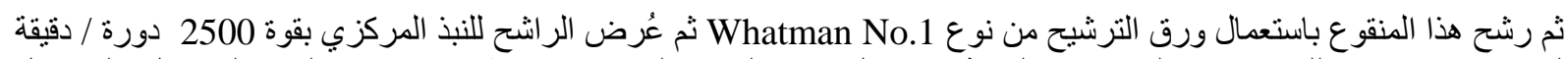

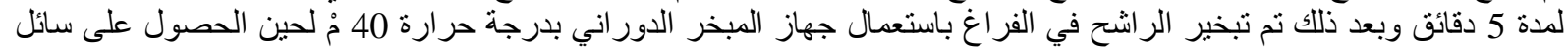

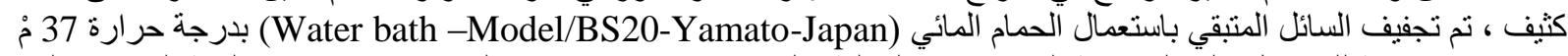

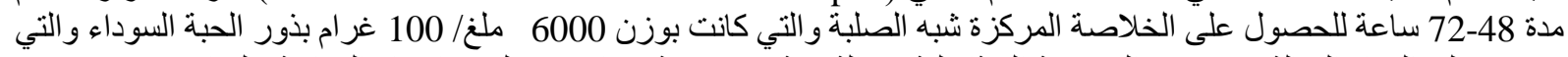

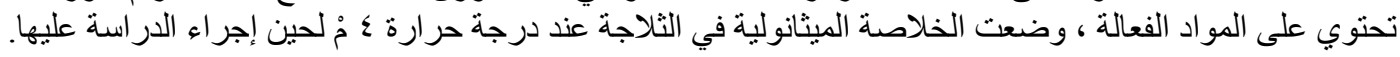

تحضير الخلاصة الميثانولية لبذور الحلبة :

Preparation of methanolic extract of Fenugreek seed 1 - 2 نظفت بذور الحلبة من الثو ائب وذذألك بإنتقائها يدوياً.

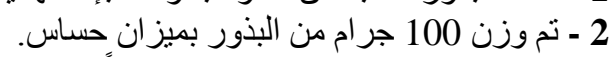

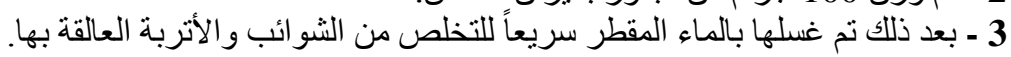

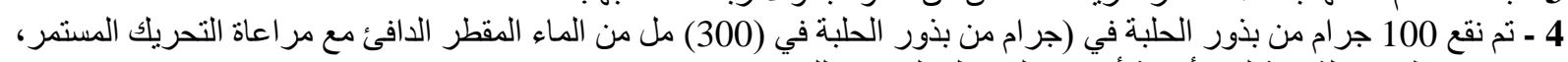

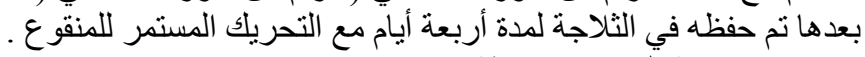

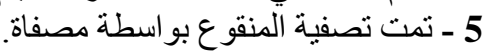

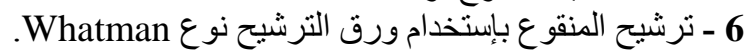

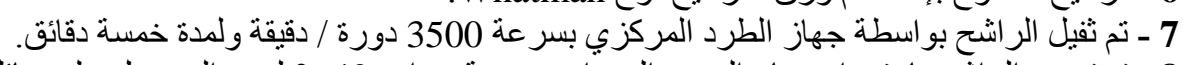

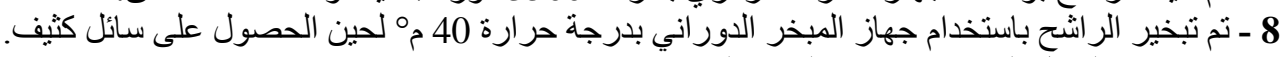

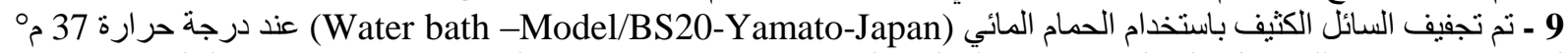

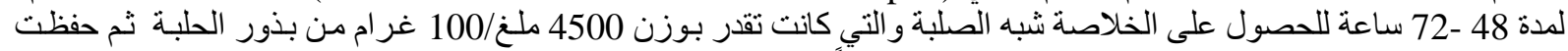
الخلاصة بالثلاجة عند درجة 4 مث لحين إجراء التجربة ، تبعاً لطريقة (Natarajan \& Dhananjayan 2007).

\section{استحداث داء السكري في الأرانب بالألوكسان :}

Alloxan-induced diabetic rabbits

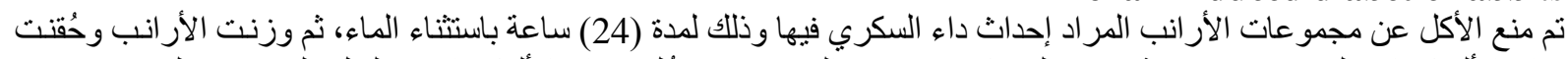

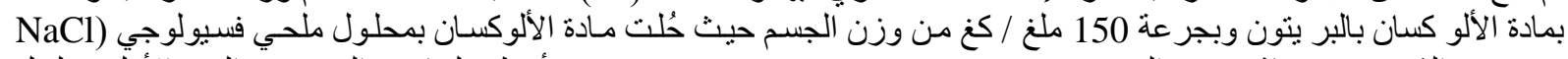

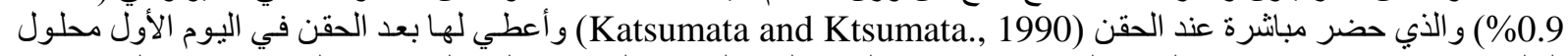

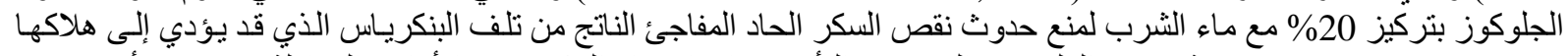

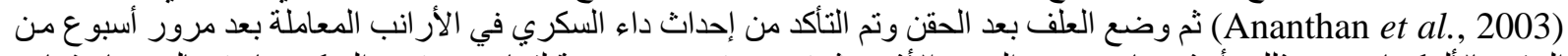

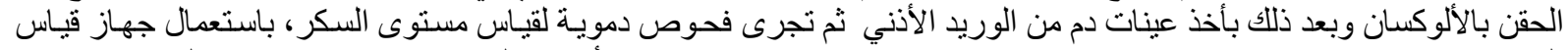

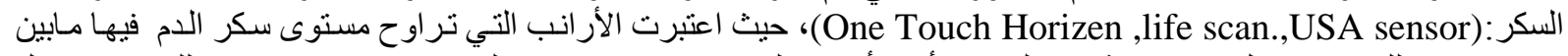

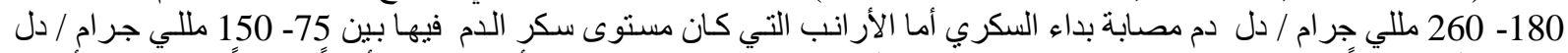

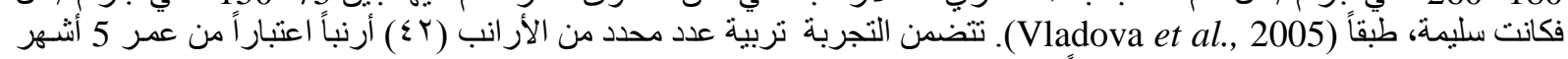

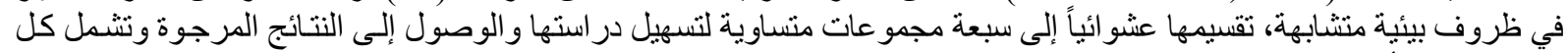

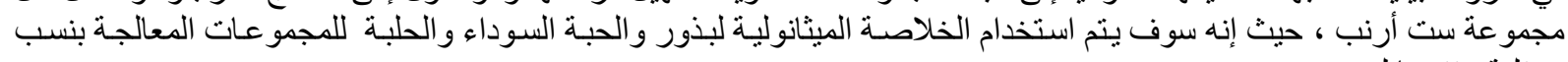
مختلفة وفق مايلي:

المجموعة الأولى : مجمو عة شاهدة تضم ست من الأر انب تم تجريعها الماء المقطر. 
المجموعة الثانية : تضم ست أرنب مصـاب بداء السكري بواسطة الألوكسان تم تجريعها بالخلاصة الميثانولية لبذور الحبة السوداء

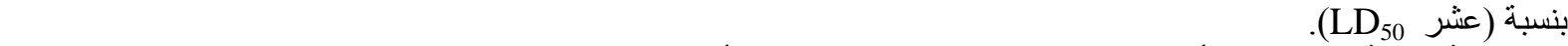
المجموعة الثالثة : تضم ست أرنب مصـاب بداء السكري بواسطة الألوكسان تم تجريعها بالخلاصة الميثانولية لبذور الحبة السوداء

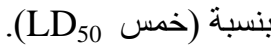
المجموعة الرابعة : تضم ست أرنب مصساب بداء السكري بواسطة الألوكسان تم تجريعها بالخلاصة الميثانولية لبذور الحلبة بنسبة (عشر المجموعة الخامسة: تضم ست أرنب مصـاب بداء السكري بواسطة الألوكسان تم تجريعها بالخلاصة الميثانولية لبذور الحلبة بنسبة

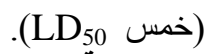

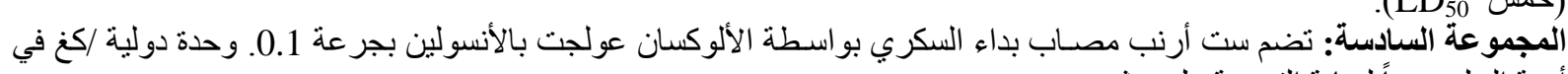

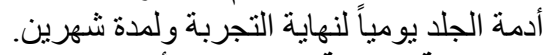
المجموعة البنابعة : تضم ست أر أنب مصنسابه بداء السكري بواسطة الألوكسان تركت بدون معالجة حتى نهاية التجربة.

جمع عينات الام: Collection of blood sample

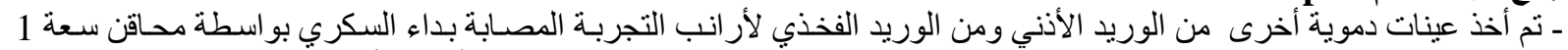

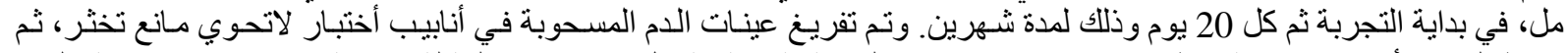

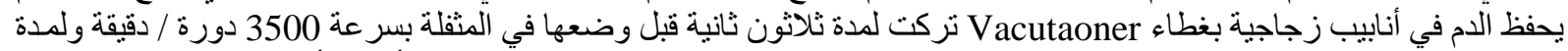

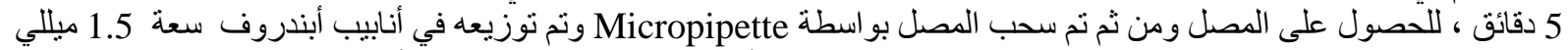

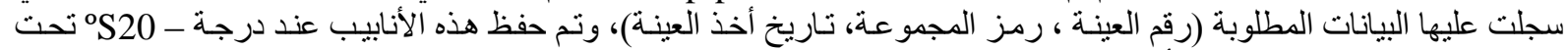
الصفر في المجمدة لحين إجراء الأختبار التطات اللازمة عليها.

التحليل الإحصائي Statistical analysis

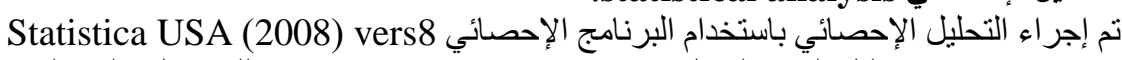

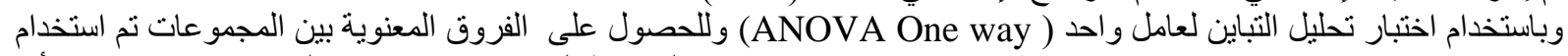

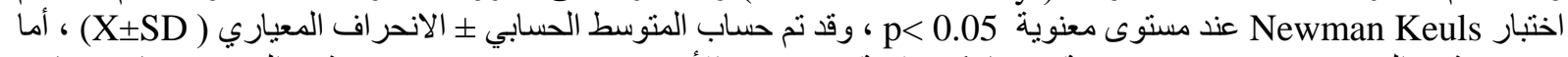

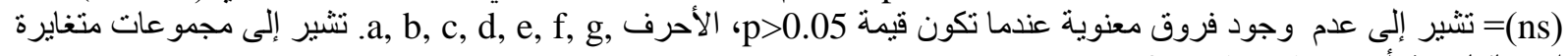
إحصائيا حيث أن

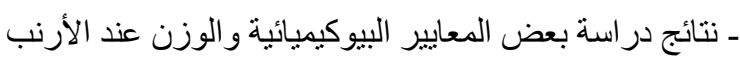

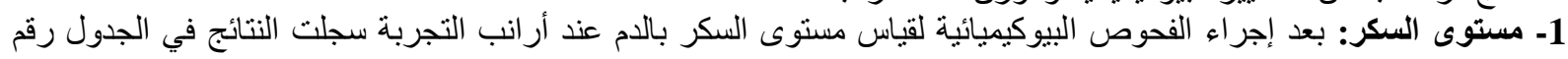

الجدول رقم ا : يبين تأثير المعاملة بالخلاصة الميثانولية لبذور الحبة السوداء والحلبة بنسبتين مختلفتين على مستوى سكر الدم mgldl

في مجموعات أر انب التجربة.

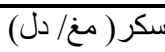

\begin{tabular}{|c|c|c|c|c|c|c|}
\hline $\mathrm{N}$ & اليوم (60) & اليوم (40) & اليوم (20) & اليوم الأول & اسم التجربة & المجمو عة \\
\hline 6 & $120.60 \pm 1.36^{\mathrm{e}}$ & $123.40 \pm 1.11^{\mathrm{d}}$ & $110.19 \pm 3.27^{\mathrm{e}}$ & $102.40 \pm 2.69^{b}$ & الضو ابط & 1 \\
\hline 6 & $137.25 \pm 0.67^{\mathrm{c}}$ & $166.19 \pm 4.28^{b c}$ & $180.57 \pm 4.19^{b c}$ & $200.35 \pm 1.19^{\mathrm{a}}$ & $\begin{array}{l}\text { حبة سوداء } 1 / 10 \mathrm{LD}_{50} \\
\text { حاء }\end{array}$ & 2 \\
\hline 6 & $123.51 \pm 0.47^{d}$ & $154.30 \pm 3.00^{\mathrm{c}}$ & $171.71 \pm 2.73^{c}$ & $200.14 \pm 1.84^{\mathrm{a}}$ & $\begin{array}{l}\text { حبة سوداء } 1 / 5 \mathrm{LD}_{50} \\
\text { حواء }\end{array}$ & 3 \\
\hline 6 & $143.85 \pm 0.53^{b}$ & $170.85 \pm 2.57^{b}$ & $189.31 \pm 4.69^{b}$ & $200.21 \pm 1.74^{\mathrm{a}}$ & $\begin{array}{c}\text { 1/10LD } \\
\text { حلبة }\end{array}$ & 4 \\
\hline 6 & $124.55 \pm 0.96^{\mathrm{d}}$ & $157.85 \pm 1.37^{b c}$ & $175.37 \pm 2.59^{c}$ & $199.7 \pm 1.80^{\mathrm{a}}$ & $\begin{array}{c}1 / 5 \mathrm{LD}_{50} \\
\text { حلبة }\end{array}$ & 5 \\
\hline 6 & $119.32 \pm 0.61^{\mathrm{e}}$ & $133.51 \pm 3.34^{d}$ & $160.56 \pm 1.73^{d}$ & $199.11 \pm 0.71^{\mathrm{a}}$ & أنسولين & 6 \\
\hline 6 & $217.52 \pm 1.50^{\mathrm{a}}$ & $213.33 \pm 7.25^{\mathrm{a}}$ & $210.67 \pm 4.52^{a}$ & $200.00 \pm 0.70^{\mathrm{a}}$ & الألو كسان & 7 \\
\hline
\end{tabular}

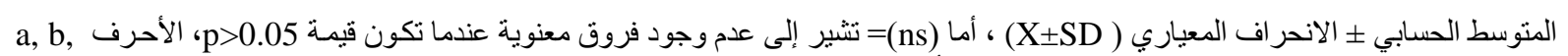

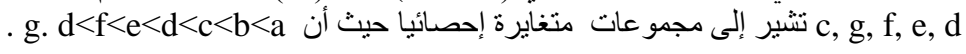


نلاحظ من الجدول رقم (1) زيادة معنوية (p<0.05) في مستوى سكر الدم في كافة مجموعات أرانب التجربة التي أحدث فيها داء

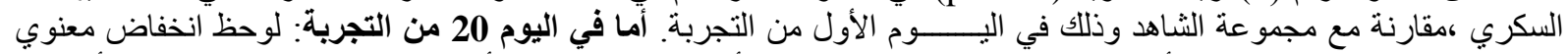

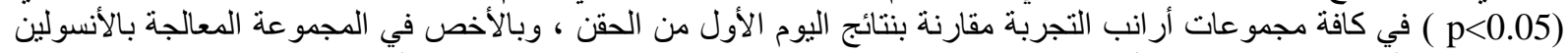

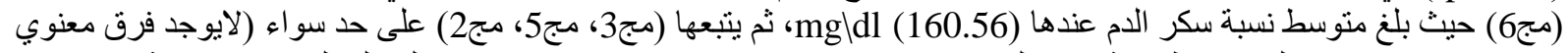

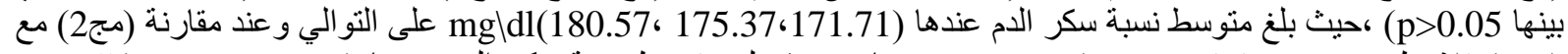

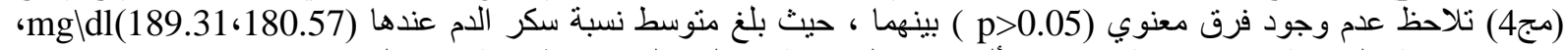

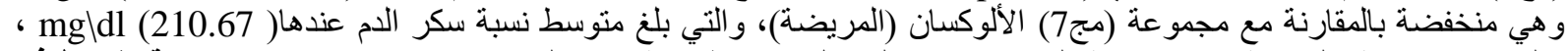

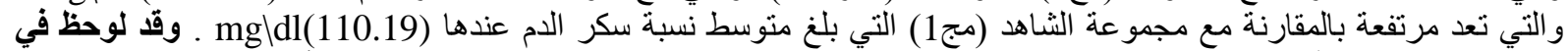

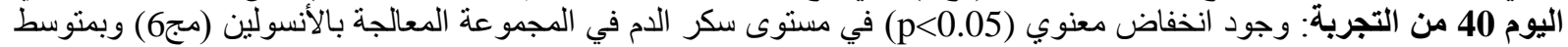

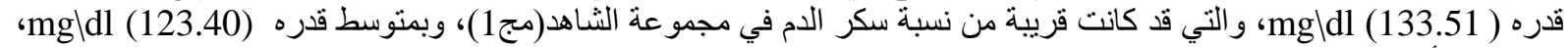

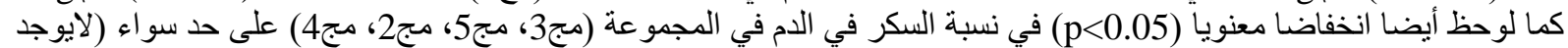

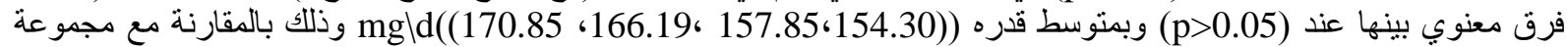

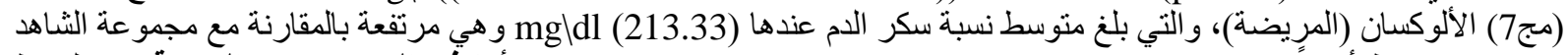

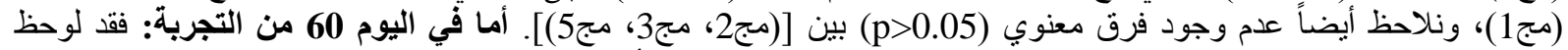

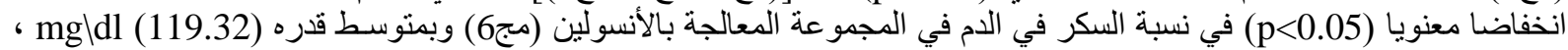

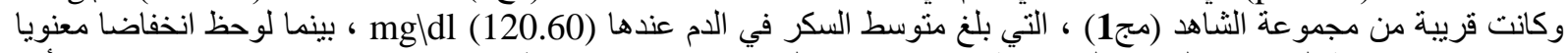

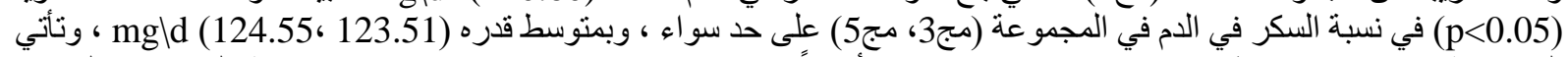

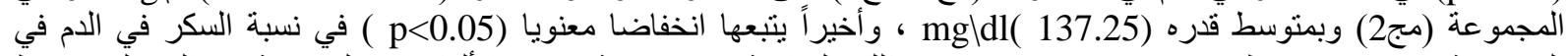

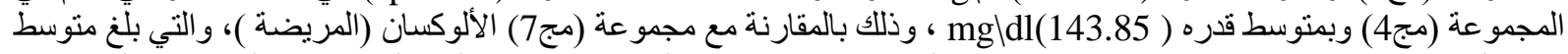
سكر الدم عندها ( mgldl(217.52 ،وهو مرتفع بالمقارنة مع مجموعة الثاهد (مج1) ، التي بلغ منوسط السكر في الدم عندها

.mgldl (120.60)

2- مستوى الكولسترول: بعد إجر اء الفحوص البيوكيميائية لقياس مستوى الكولسترول الكلي بالدم عند أر انب التجربة سجلت النتائج

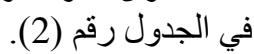

الجدول رقم ب : يبين تأثير المعاملة بالخلاصة الميثانولية لبذور الحبة السوداء و الحلبة بنسبتين مختلفتين على مستوى كولسترول الكلي للام) (mgldl في مجمول عات أر انب التجربة.

\begin{tabular}{|c|c|c|c|c|c|c|}
\hline \multicolumn{7}{|c|}{ الكوليسترول الكلي ( مغ/دل) } \\
\hline $\mathrm{N}$ & اليوم (60) & اليوم (40) & اليوم (20) & اليوم الأول & اسم التجربة & المجمو عة \\
\hline 6 & $64.23 \pm 0.44^{\mathrm{c}}$ & $60.52 \pm 0.64^{\mathrm{g}}$ & $57.27 \pm 0.38^{\mathrm{g}}$ & $55.30 \pm 0.91^{\mathrm{b}}$ & الضو ابط & 1 \\
\hline 6 & $72.35 \pm 0.33^{b}$ & $123.22 \pm 0.37^{\mathrm{c}}$ & $150.71 \pm 0.89^{\mathrm{c}}$ & $155.75 \pm 0.37^{\mathrm{a}}$ & $\begin{array}{c}\text { حبة سوداء } 1 / 10 \mathrm{LD}_{50} \\
\text { حاء }\end{array}$ & 2 \\
\hline 6 & $67.05 \pm 0.27^{\mathrm{c}}$ & $100.35 \pm 0.60^{\mathrm{e}}$ & $135.23 \pm 0.50^{\mathrm{e}}$ & $155.00 \pm 0.70^{\mathrm{a}}$ & $\begin{array}{l}\text { حبة سوداء } 1 / 5 \mathrm{LD}_{50} \\
\text { داء }\end{array}$ & 3 \\
\hline 6 & $73.37 \pm 0.31^{\mathrm{b}}$ & $125.14 \pm 0.22^{b}$ & $153.91 \pm 0.32^{b}$ & $154.20 \pm 0.87^{\mathrm{a}}$ & $\begin{array}{r}\text { 1/10LD } \\
\text { حلنة }\end{array}$ & 4 \\
\hline 6 & $67.71 \pm 0.37^{\mathrm{c}}$ & $105.14 \pm 0.27^{\mathrm{d}}$ & $137.00 \pm 0.31^{\mathrm{d}}$ & $155.30 \pm 0.59^{\mathrm{a}}$ & $\begin{array}{c}\text { 1/5 } \mathrm{LD}_{50} \\
\text { حلبة }\end{array}$ & 5 \\
\hline 6 & $64.75 \pm 0.22^{c}$ & $90.91 \pm 0.71^{\mathrm{f}}$ & $125.50 \pm 0.44^{\mathrm{f}}$ & $154.22 \pm 0.15^{\mathrm{a}}$ & أنسولين & 6 \\
\hline 6 & $167.22 \pm 0.35^{\mathrm{a}}$ & $163.33 \pm 0.58^{\mathrm{a}}$ & $160.67 \pm 0.45^{\mathrm{a}}$ & $155.20 \pm 0.58^{\mathrm{a}}$ & الألو كسان & 7 \\
\hline
\end{tabular}

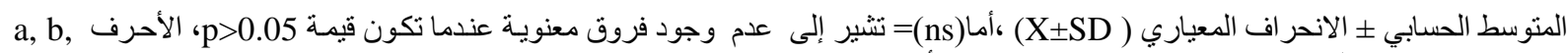
. g. d<f<e<d<c<b<a تثير إلى مجموعات متغايرة إحصائيا حيث أن أن c, g, f, e, d

نلاحظ من الجدول رقم (2) زيادة معنوية 0.05 p بي مسنوى الكولسترول الكلي في كافة مجمو عات أرانب التجربة التي أحدث فيها داء السكري ، مقارنة مع مجمو عة أر انب الثاهد و التي بلغ متوسط الكولسترول الكلي عندها (55.30) mgldl وذلك في اليوم الأول 
أما في اليوم (20 ، 40 ) من التجربة فقد انخفاضا معنويا (م) (0.05 ) ) في كافة مجموعات أرانب التجربة المعالجة على التوالي

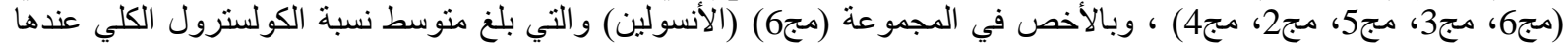

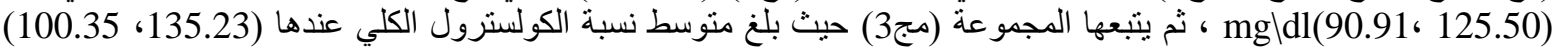

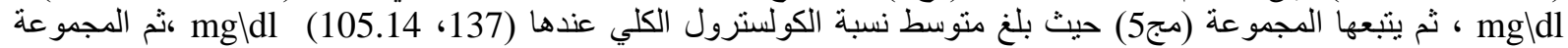

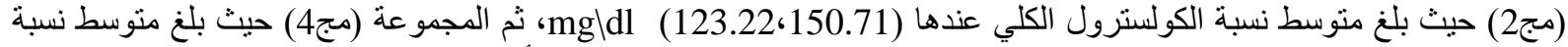

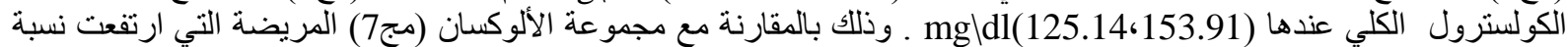

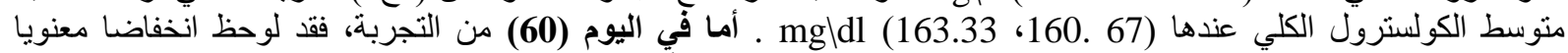

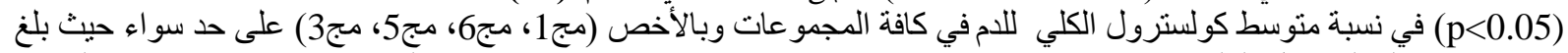

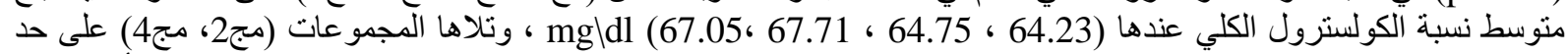

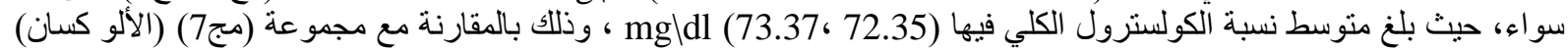

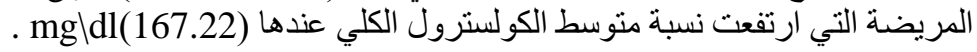

3 - مستوى ثلاثي الجليسريدات: بعد إجراء الفحوص البيوكيمبائية لقياس مستوى ثلاثي الجليسريدات بالدم عند أر انب التجربة سجلت

النتائج الموضحة في الجدول رقم (ب).

\begin{tabular}{|c|c|c|c|c|c|c|}
\hline \multicolumn{7}{|c|}{ ثلاثي الجليسريدات ( مغ/ دل) } \\
\hline $\mathrm{N}$ & اليوم (60) & اليوم (40) & اليوم (20) & اليوم الأول & اسم التجربة & المجمو عة \\
\hline 6 & $50 \pm 0.44^{d}$ & $47.14 \pm 0.31^{\mathrm{f}}$ & $44.20 \pm 0.37^{\mathrm{g}}$ & $40.33 \pm 0.57^{b}$ & الضو ابط & 1 \\
\hline 6 & $63.32 \pm 0.28^{c}$ & $72.25 \pm 0.53^{c}$ & $88.30 \pm 0.34^{\mathrm{c}}$ & $100.23 \pm 0.47^{\mathrm{a}}$ & $\begin{array}{l}\text { حبة سوداء } 1 / 10 D_{50} \\
\text { حواء }\end{array}$ & 2 \\
\hline 6 & $52.32 \pm 0.28^{\mathrm{d}}$ & $62.2 \pm 0.58^{\mathrm{d}}$ & $83.14 \pm 0.13^{\mathrm{e}}$ & $99.00 \pm 0.63^{\mathrm{a}}$ & 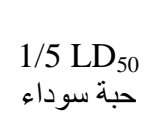 & 3 \\
\hline 6 & $65.3 \pm 0.58^{c}$ & $75.00 \pm 0.44^{\mathrm{b}}$ & $90.100 \pm 0.40^{\mathrm{b}}$ & $99.84 \pm 0.35^{\mathrm{a}}$ & $\begin{array}{c}\text { 1/10LD } \\
\text { حلبة }\end{array}$ & 4 \\
\hline 6 & $52.22 \pm 0.37^{\mathrm{d}}$ & $63.4 \pm 0.40^{\mathrm{d}}$ & $84.70 \pm 0.24^{\mathrm{d}}$ & $100.42 \pm 0.92^{\mathrm{a}}$ & $\begin{array}{c}\text { 1/5 LD } \\
\text { حلبة }\end{array}$ & 5 \\
\hline 6 & $51.83 \pm 0.17^{\mathrm{d}}$ & $60.33 \pm 0.32^{\mathrm{e}}$ & $72.14 \pm 0.48^{f}$ & $100.00 \pm 0.70^{a}$ & أنسولين & 6 \\
\hline 6 & $115.67 \pm 0.37^{\mathrm{a}}$ & $110.95 \pm 0.47^{\mathrm{a}}$ & $104.00 \pm 0.63^{\mathrm{a}}$ & $99.43 \pm 0.50^{\mathrm{a}}$ & الألو كسان & 7 \\
\hline
\end{tabular}

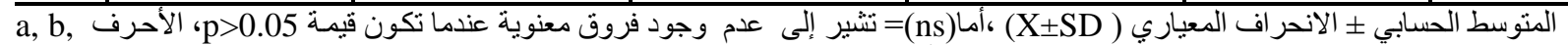

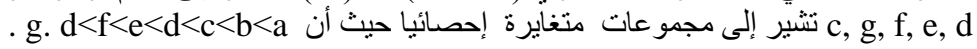

نلاحظ من الجدول رقم (3) زيادة معنوية (p0.05) في مستوى ثناثي الجليسريدات في كافة مجمو عات أرانب التجربة التي أحدث

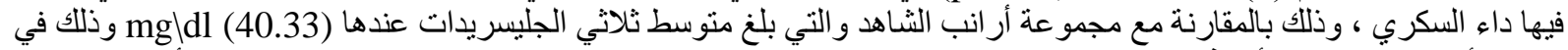

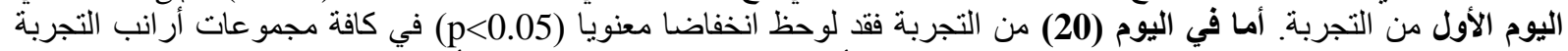

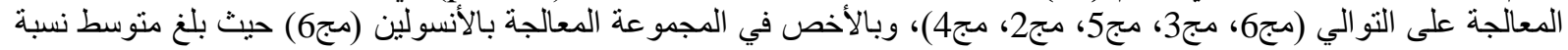

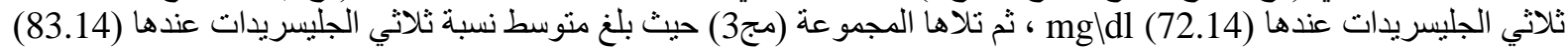

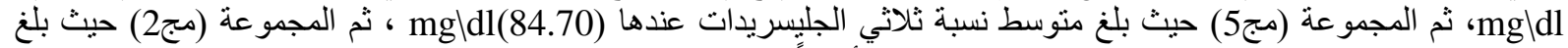

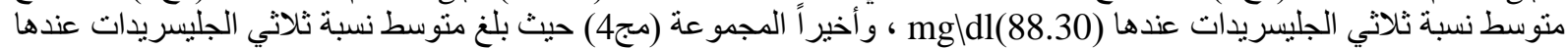

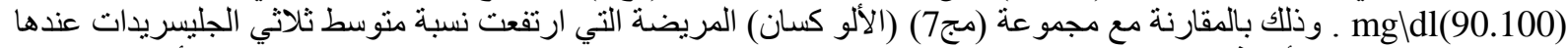

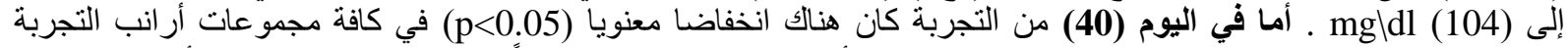

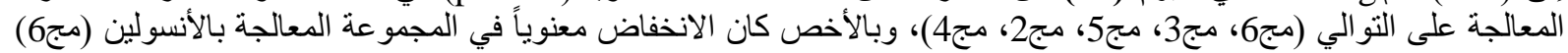

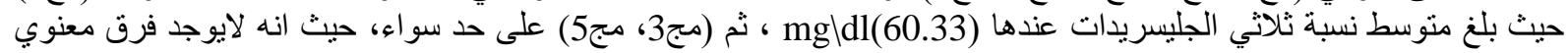

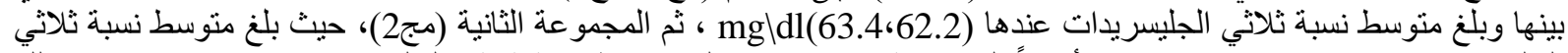

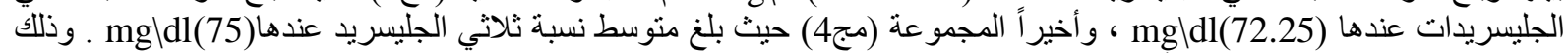

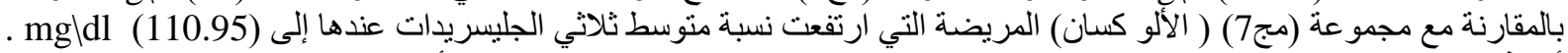

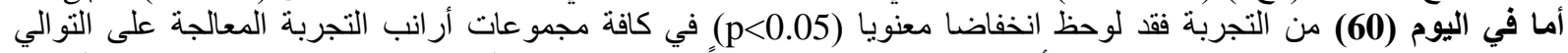

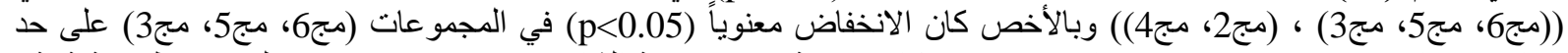

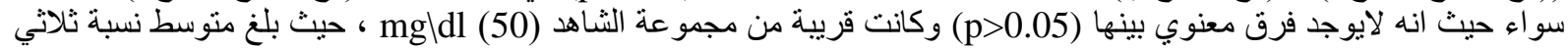




\section{Assiut Vet. Med. J. Vol. 61 No. 147 October 2015}

الجليسريدات عند المجموعات السابقة الذكر (51.83، 52.22،

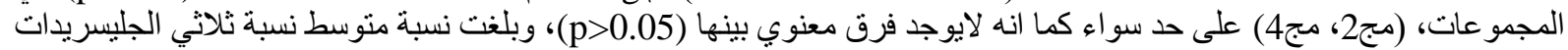

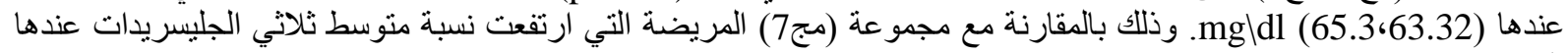
إلى

4- مستوى الليبو بروتينات منذفضة الكثافة (LDL): بعد إجراء الفحوص البيوكيميائية لقياس مستوى LDL مغ/ دل بالام عند

أر انب التجربة سجلت النتائج في الجدول رقم (4).

الجدول رقم (๕) : تأثير المعاملة بالخلاصة الميثانولية لبذور الحبة السوداء والحلبة بنسبتين مختلفتين على مستوى الليبو بروتينات

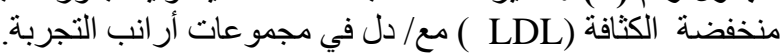

\begin{tabular}{|c|c|c|c|c|c|c|}
\hline \multicolumn{7}{|c|}{ LDL } \\
\hline $\mathrm{N}$ & اليوم (60) & اليوم (40) & اليوم (20) & اليوم الأول & اسم التجربة & المجموعة \\
\hline 6 & $87.80 \pm 0.38^{\mathrm{c}}$ & $82.15 \pm 0.45^{f}$ & $77.49 \pm 0.27^{\mathrm{g}}$ & $75.25 \pm 0.33^{b}$ & الضو ابط & 1 \\
\hline 6 & $94.50 \pm 0.38^{b}$ & $119.86 \pm 0.32^{b}$ & $125.22 \pm 0.19^{c}$ & $127.80 \pm 0.47^{\mathrm{a}}$ & $\begin{array}{l}\text { حبة سوداء } 1 / 10 \mathrm{LD}_{50} \\
\end{array}$ & 2 \\
\hline 6 & $86.00 \pm 0.63^{c}$ & $115.00 \pm 0.44^{\mathrm{d}}$ & $122.33 \pm 0.19^{\mathrm{e}}$ & $126.90 \pm 0.63^{\mathrm{a}}$ & 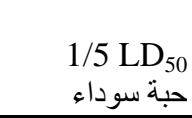 & 3 \\
\hline 6 & $95.50 \pm 0.44^{\mathrm{b}}$ & $121.09 \pm 0.25^{b}$ & $126.25 \pm 0.33^{b}$ & $127.75 \pm 0.35^{\mathrm{a}}$ & $\begin{array}{r}\text { 1/10LD } \\
\text { حلبة }\end{array}$ & 4 \\
\hline 6 & $86.75 \pm 0.11^{\mathrm{c}}$ & $117.52 \pm 0.31^{\mathrm{c}}$ & $123.20 \pm 0.20^{\mathrm{d}}$ & $127.75 \pm 0.35^{\mathrm{a}}$ & حلبة $1 / 5 \mathrm{LD}_{50}$ & 5 \\
\hline 6 & $85.22 \pm 0.32^{c}$ & $100.35 \pm 0.67^{e}$ & $120.52 \pm 0.44^{f}$ & $126.92 \pm 0.70^{\mathrm{a}}$ & أنسولين & 6 \\
\hline 6 & $135.22 \pm 0.19^{\mathrm{a}}$ & $133.37 \pm 0.40^{\mathrm{a}}$ & $129.50 \pm 0.31^{\mathrm{a}}$ & $127.05 \pm 0.50^{\mathrm{a}}$ & الألو كسان & 7 \\
\hline
\end{tabular}

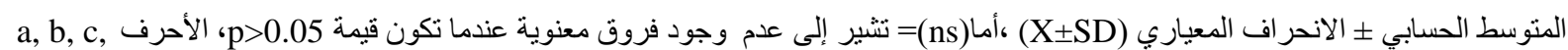

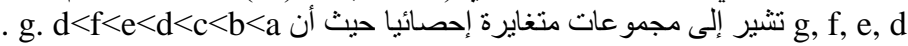

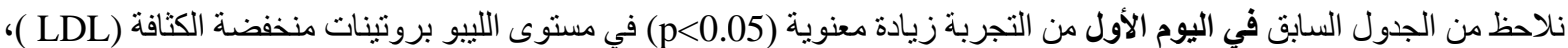

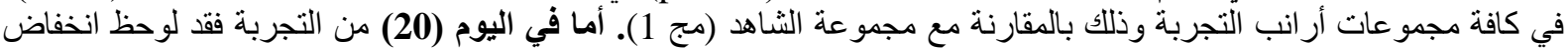

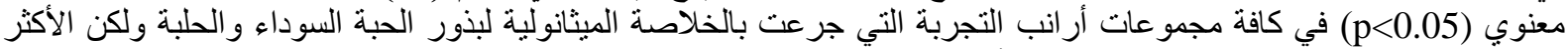

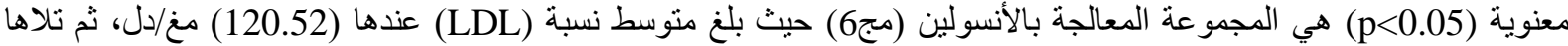

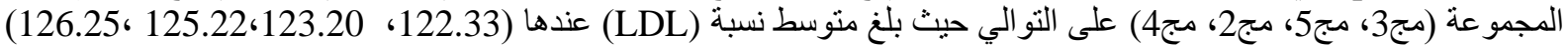

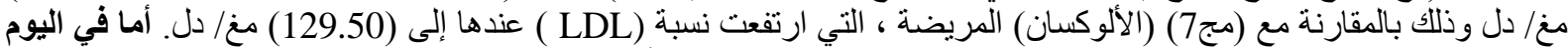

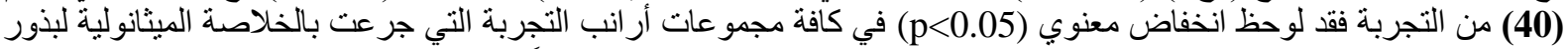

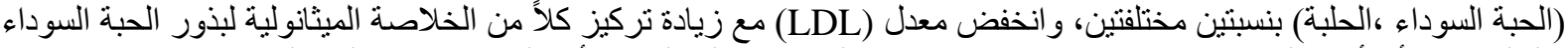

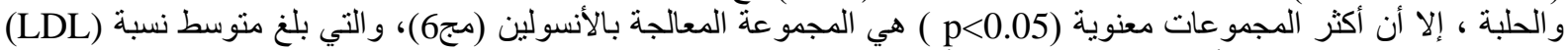

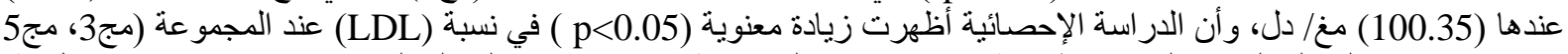

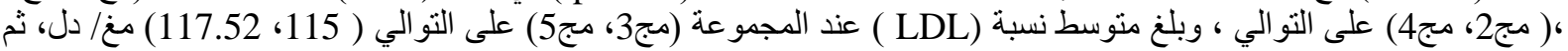

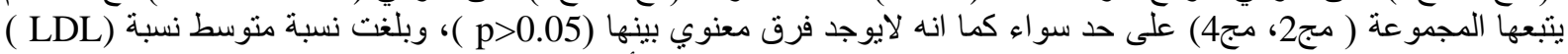

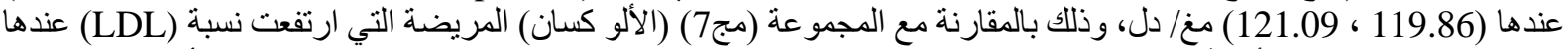

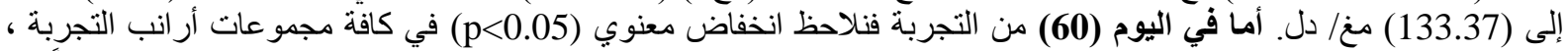

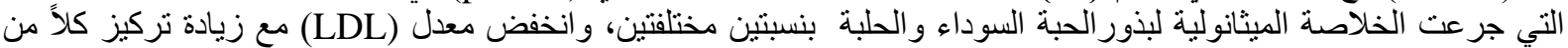

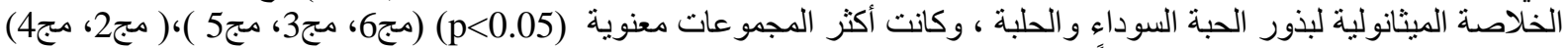

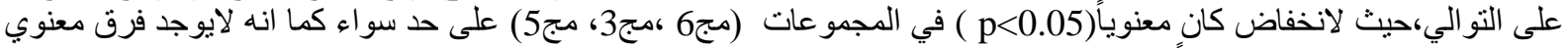

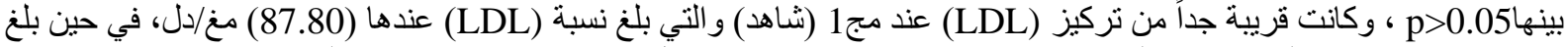

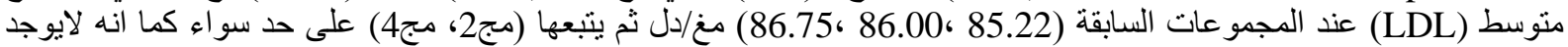

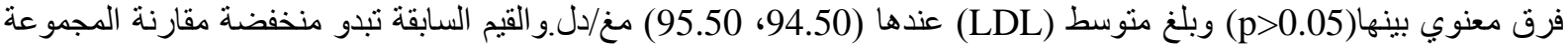

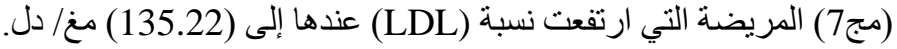


5- مستوى الليبو بروتينات عالية الكثافة (HDL): بعد إجراء الفحوص البيوكيميائية لقياس مستوى HDL مغ/ دل بالدم عند أر انب

التجربة سجلت النتائج في الجدول رقم (5).

الجدول رقم (5) تأثير المعاملة بالخلاصة الميثانولية لبذور الحبة السوداء والحلبة بنسبتين مختلفتين على مستوى اللييو بروتينات عالية الكثافة (HDL) مغ/ (5) دل في مجموعات أر انب التجربة.

الجدول رقم (•): نأثثير المعاملة بالخلاصة الميثانولية لبذور الحبة السوداء والحلبة بنسبتين مختلفتين على مستوى الليبو بروتينات

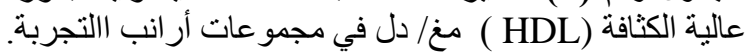

\begin{tabular}{|c|c|c|c|c|c|c|}
\hline \multicolumn{7}{|c|}{ HDL } \\
\hline $\mathrm{N}$ & اليوم (60) & اليوم (40) & اليوم (20) & اليوم (1) & اسم التجربة & المجموعة \\
\hline 6 & $44.90 \pm 0.50^{\mathrm{a}}$ & $41.52 \pm 0.31^{2}$ & $35.00 \pm 0.31^{\mathrm{a}}$ & $37.00 \pm 0.41^{b}$ & الضو ابط & 1 \\
\hline 6 & $33.46 \pm 0.47^{b}$ & $29.05 \pm 0.65^{\mathrm{c}}$ & $27.50 \pm 0.31^{\text {cd }}$ & $27.00 \pm 0.27^{\mathrm{a}}$ & $\begin{array}{l}\text { حبة سوداء } 1 / 10 \mathrm{LD}_{50} \\
\text { حاء }\end{array}$ & 2 \\
\hline 6 & $42.55 \pm 0.46^{\mathrm{a}}$ & $37.69 \pm 0.44^{b}$ & $29.12 \pm 0.62^{c}$ & $27.55 \pm 0.47^{\mathrm{a}}$ & $\begin{array}{l}\text { حبة سوداء } 1 / 5 \mathrm{LD}_{50} \\
\text { حاء }\end{array}$ & 3 \\
\hline 6 & $31.30 \pm 0.58^{b}$ & $28.76 \pm 0.74^{c}$ & $27.00 \pm 0.35^{\mathrm{cd}}$ & $26.25 \pm 0.19^{a}$ & $\begin{array}{c}\text { حلبة } 1 / 10 D_{50} \\
\text { حلب }\end{array}$ & 4 \\
\hline 6 & $42.51 \pm 1.05^{\mathrm{a}}$ & $36.50 \pm 0.70^{b}$ & $28.51 \pm 0.50^{\mathrm{c}}$ & $27.33 \pm 0.41^{\mathrm{a}}$ & $\begin{array}{c}1 / 5 \mathrm{LD}_{50} \\
\text { حلبة }\end{array}$ & 5 \\
\hline 6 & $44.45 \pm 0.35^{\mathrm{a}}$ & $40.00 \pm 0.31^{\mathrm{a}}$ & $31.23 \pm 0.45^{b}$ & $26.75 \pm 0.37^{\mathrm{a}}$ & أنسولين & 6 \\
\hline 6 & $20.00 \pm 0.31^{\mathrm{c}}$ & $21.95 \pm 0.59^{\mathrm{d}}$ & $23.20 \pm 0.66^{\mathrm{e}}$ & $27.00 \pm 0.26^{\mathrm{a}}$ & الألو كسان & 7 \\
\hline
\end{tabular}

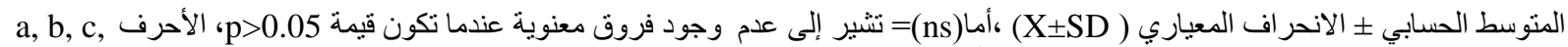

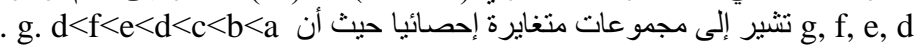

نلاحظ من الجدول السابق في اليوم الأول من التجربة وجود انخفاض معنوي (1)0.05) في مستوى اللييو بروتينات عالية الكتافة

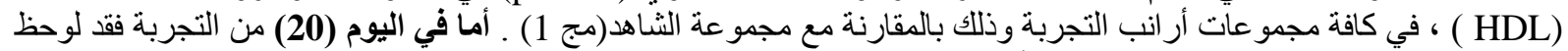

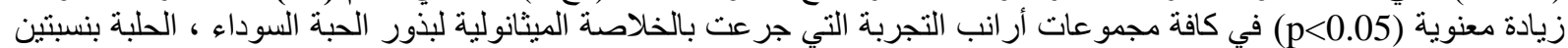

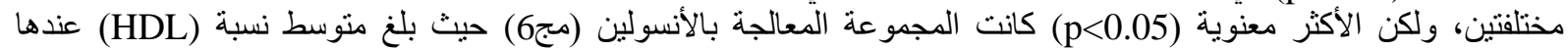

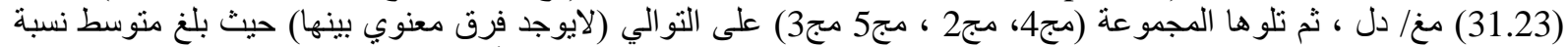
(HDL)

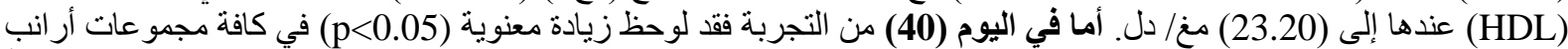

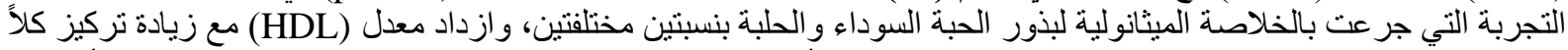

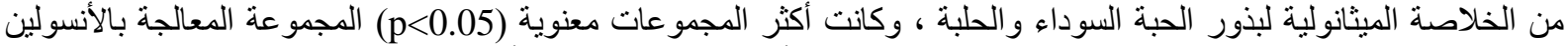

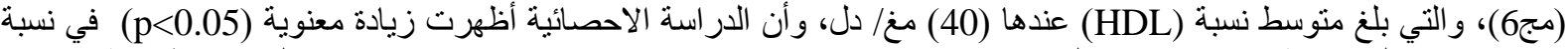

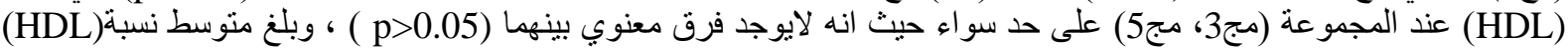

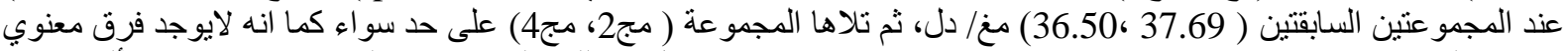

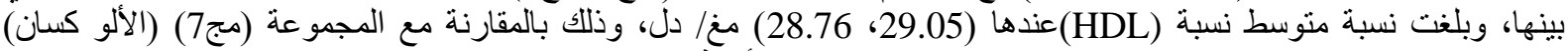

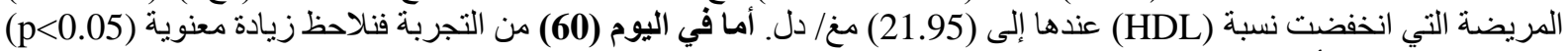

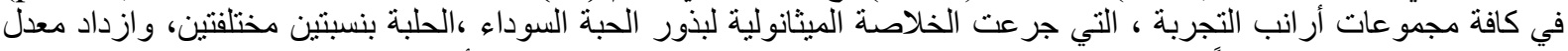

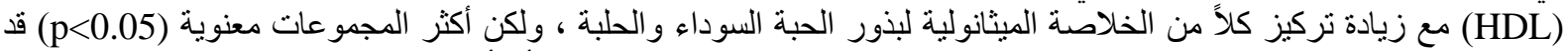

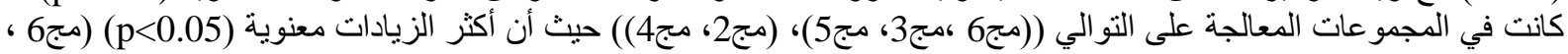

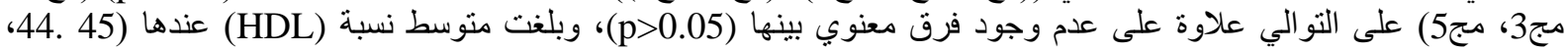

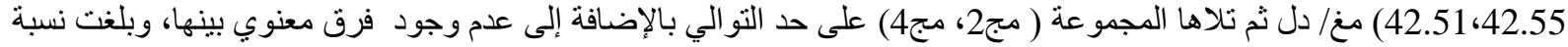

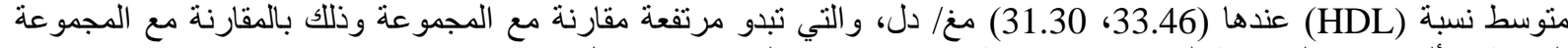

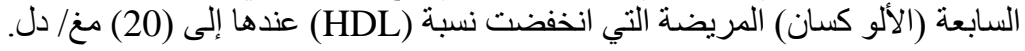




\title{
DISCUSSION
}

\author{
المناقشة
}

Effect of of methalonic : أولاً تأثير الخلاصة الميثانولية لبذور (الحبة السوداء، الحلبة) على مستوى السكر في مصل الدام extract of Fenugreek and Nigella Sativa seeds on glucose of blood serum level

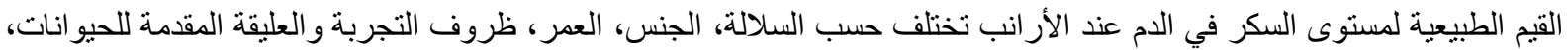

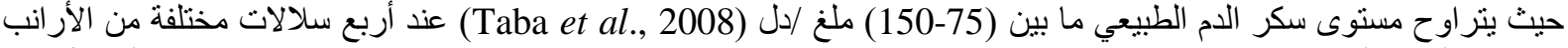

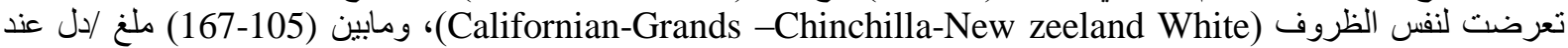

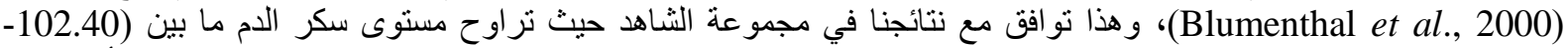

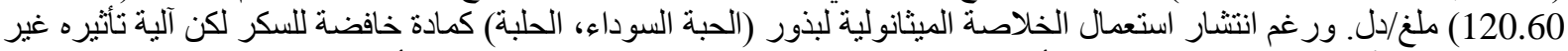

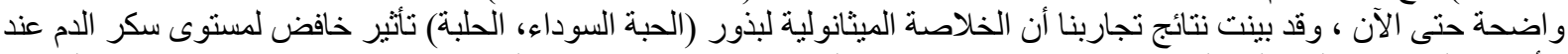

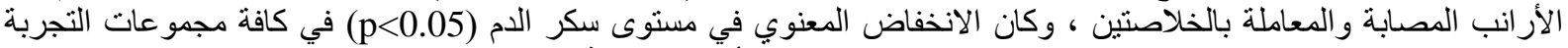

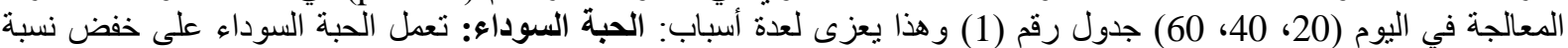

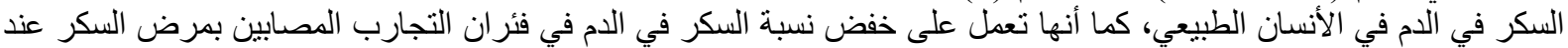

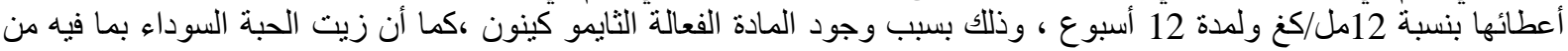

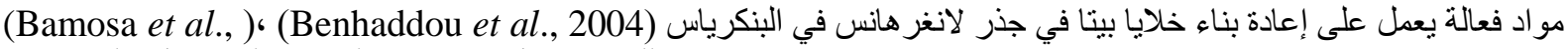

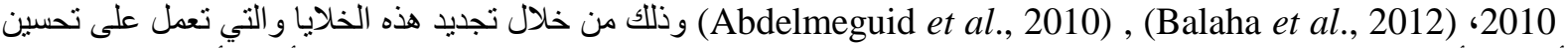

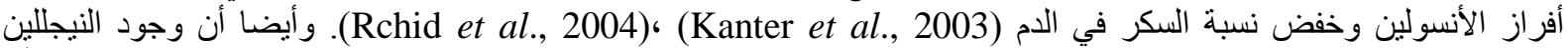

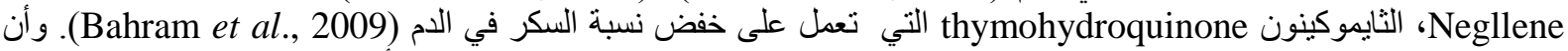

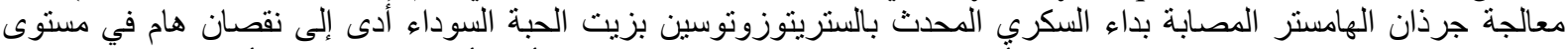

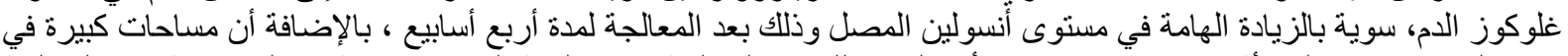

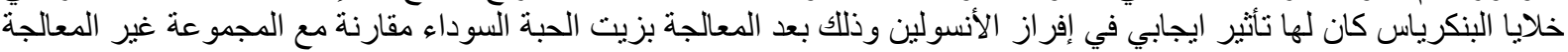

.(Ayed et al., 2011)

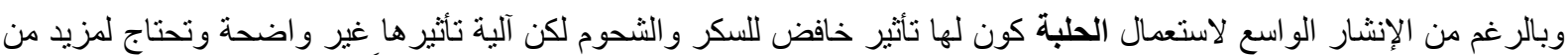

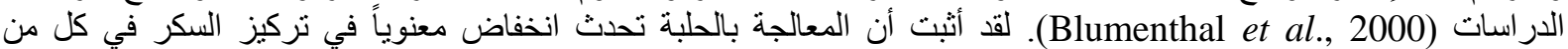

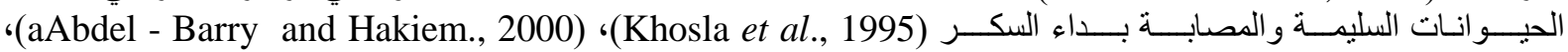

.(Xue et al., 2007)

أن المواد التي لها القابلية على خفض الغلوكوز في الدم تظهر تأثير ها في الجسم عن طريق الآليات التالية : تحفيز خلايا بيتا في

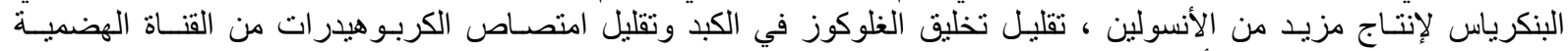

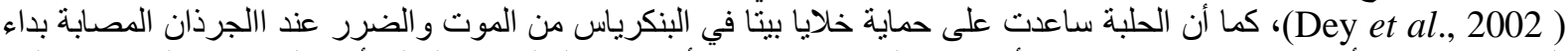

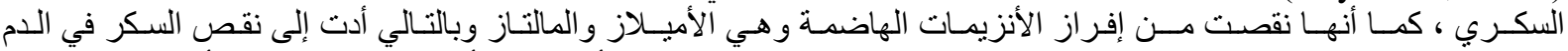

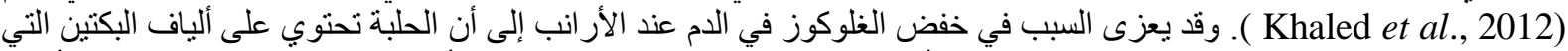

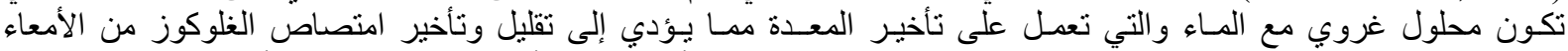
Dioxygenase (Hannana et al., 2003) (Mader, Z. \& Shomer, Z. 1998).

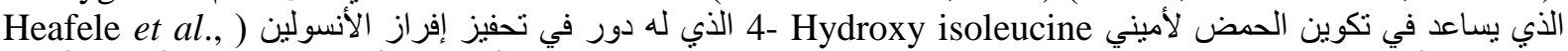

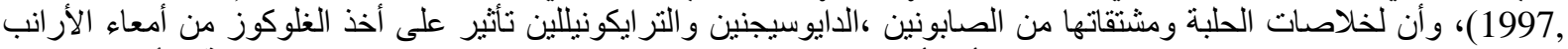

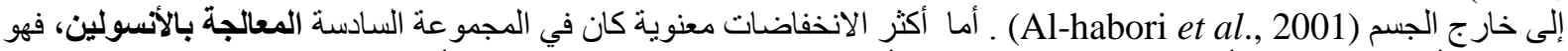

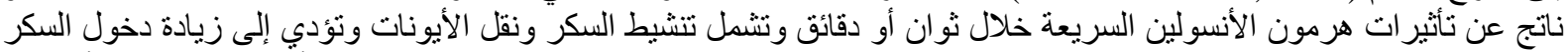

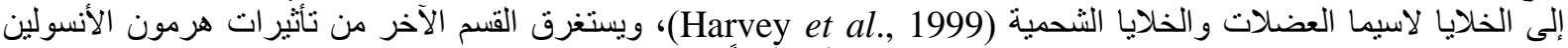

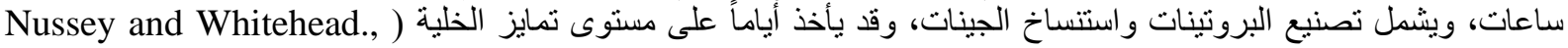

.(2001

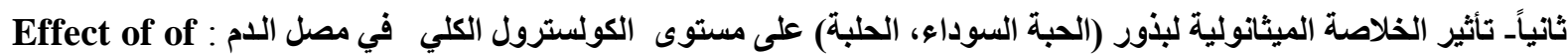
methalonic extract of Fenugreek and Nigella Sativa seeds on serum total cholesterol blood level

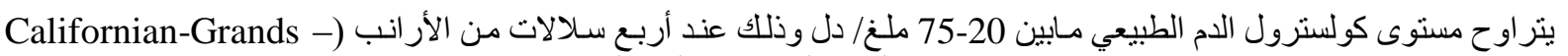
(Chinchilla-New zeeland White) ، وقد تعرضت لنفس الظروف و والمعاملة (Taba et al., 2008).

ولقد نو افقت مستويات الكوليسترول الكلي في مجمو عة الثاهد في نتائجنا مع هذه القيم (55.30-64.23) ملغ/ دل، حيث بلغ متوسط مستوى كوليسترول الدم (55.8) ملغ/ دل 


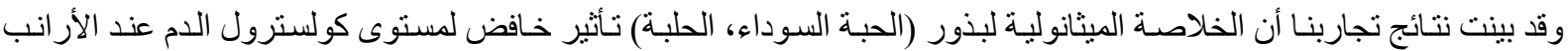

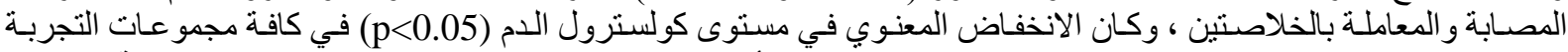

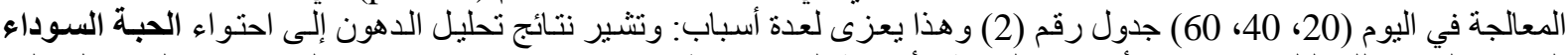

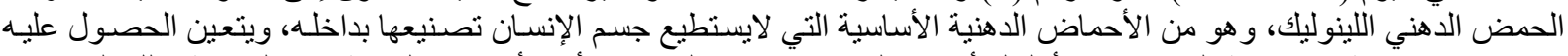

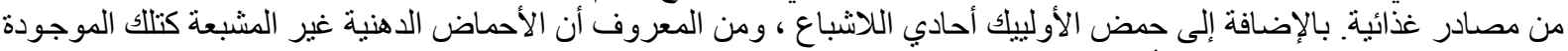

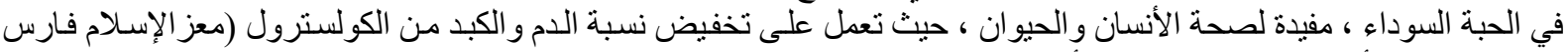

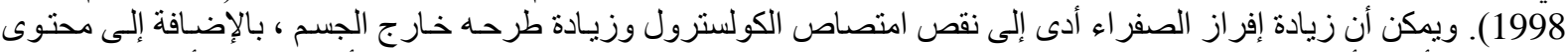

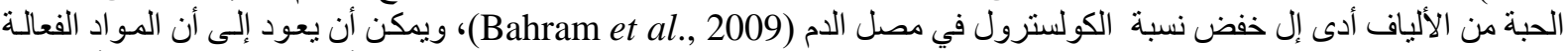

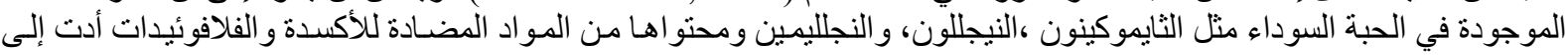

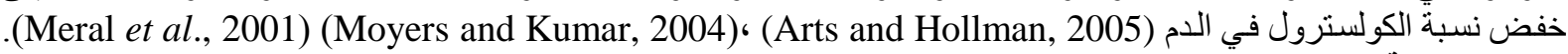

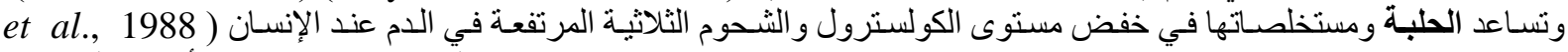

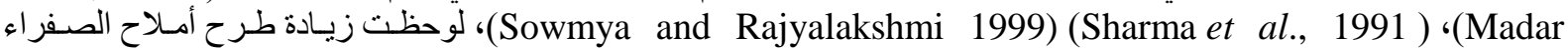

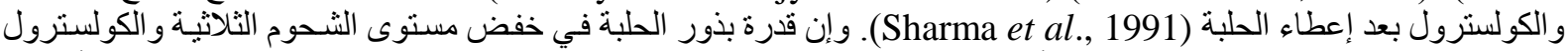

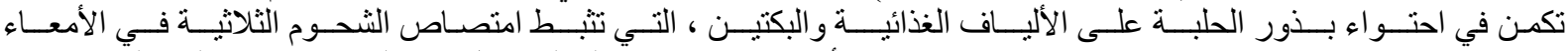

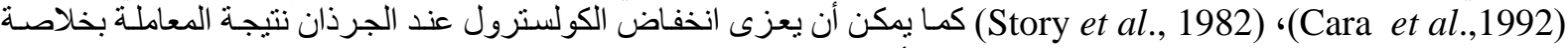
الحلبة الميثانولية لبذور الحلبة إلى تفاعل الصنابونين ميع أملاح الصفر اء في في القناة الهضيمية (Stark and Madar et al., 1993)،

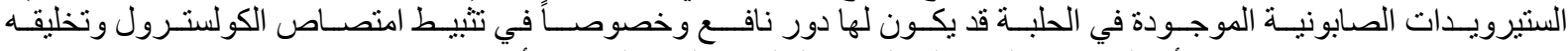
وأن الخلاصـة الميثانولية لبذور الحلبة عملت على منع أنزيمات رئيسية من الاستقلاب وامتصـاص

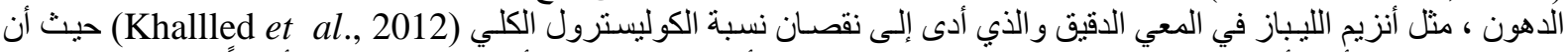

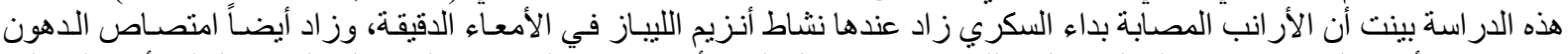

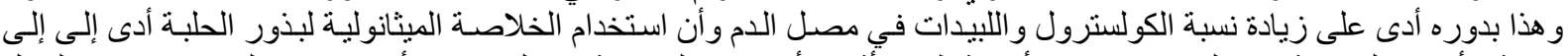

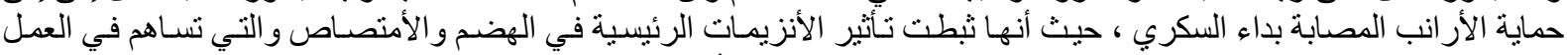

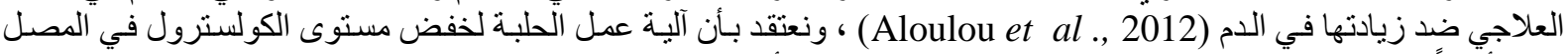

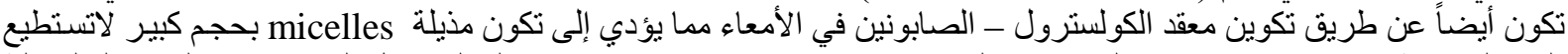

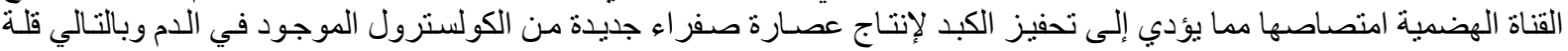

مستو اه في الدم (القيم وزملاؤه 2002).

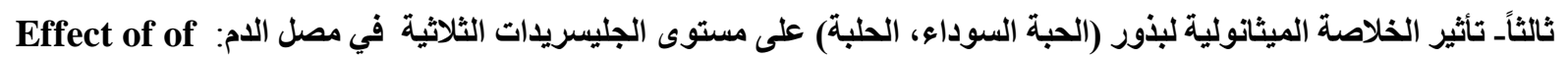
methalonic extract of Fenugreek and Nigella Sativa seeds on serum triglycerides blood level

يتر اوح المستوى الطبيعي للثحوم الثلاثية في مصل الدم عند الأرانب مابين 37-65 ملغ/ دل (Taba et al., 2008). وقد تو افقت

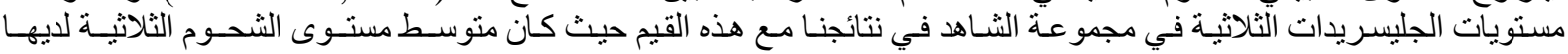

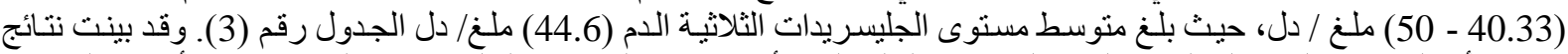

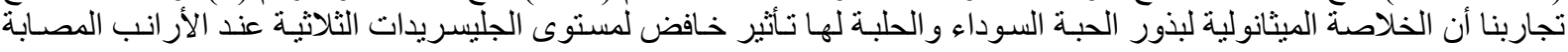

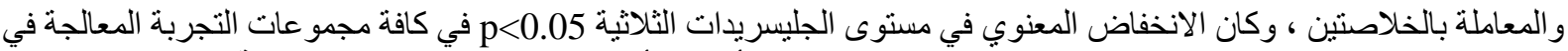

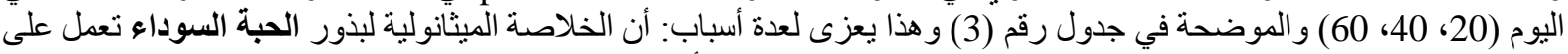

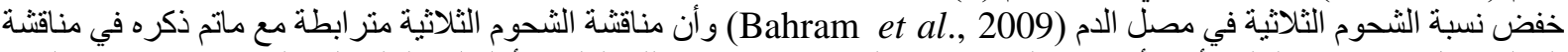

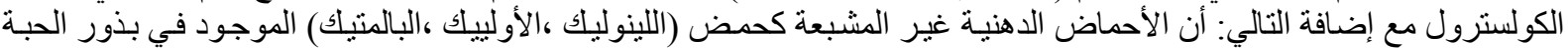

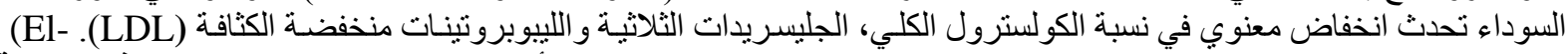

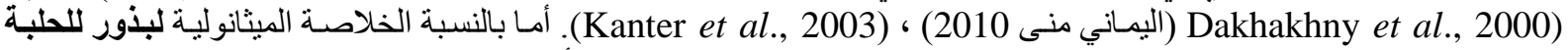

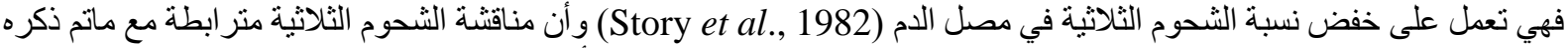

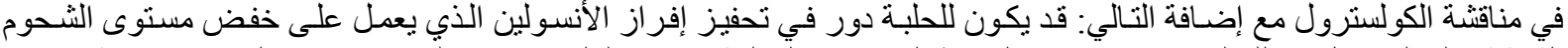

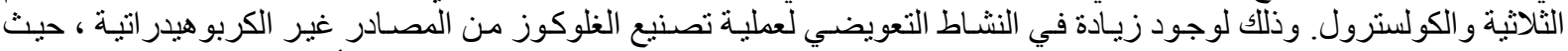

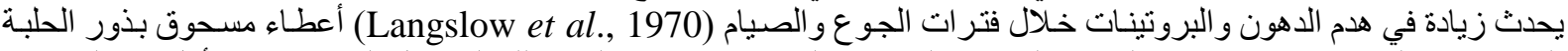

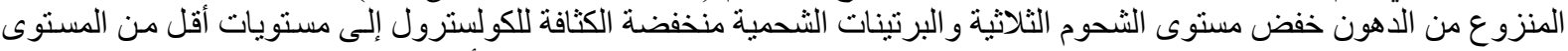

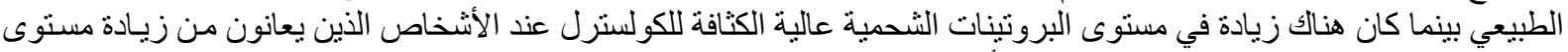

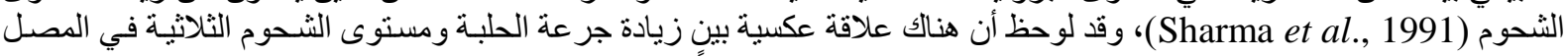

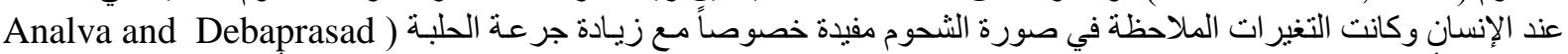

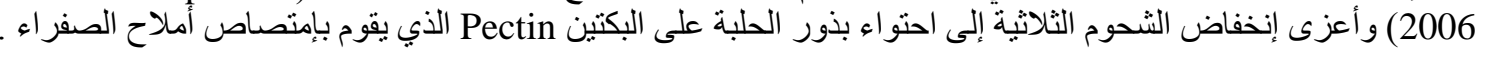

رابعاً تأثير الخلاصة الميثانولية لبذور (الحبة السوداء، الحلبة) على مستوى نسبة الليبوبروتينات منذفضة الكثافة (LDL) في مصل الام: - Effect of of methalonic extract of Fenugreek and Nigella Sativa seeds on serum low density lipoproteins blood level 


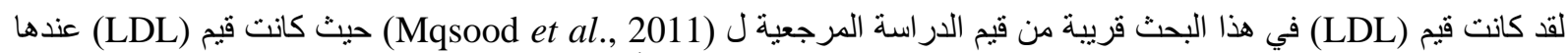

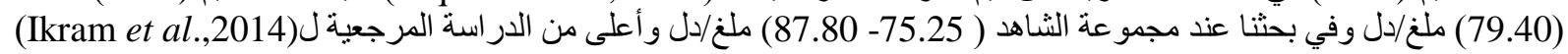

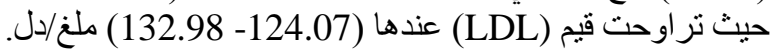

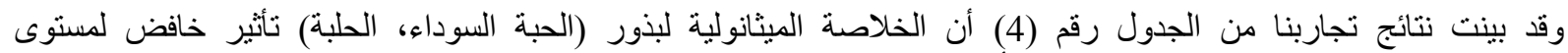

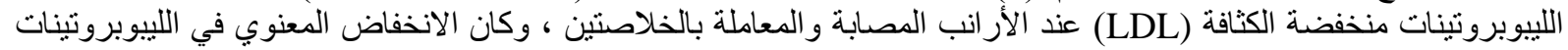

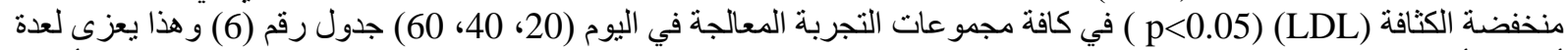

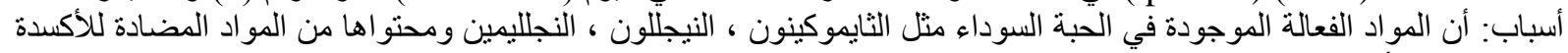

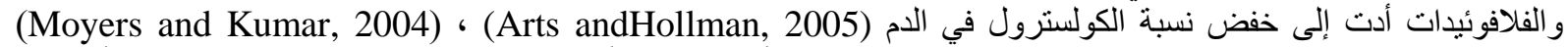

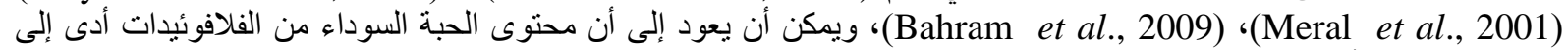

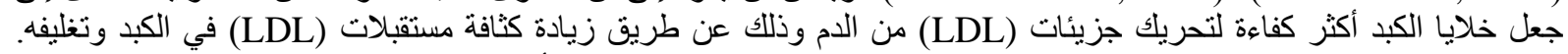

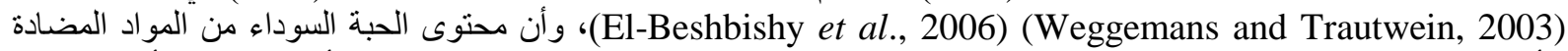

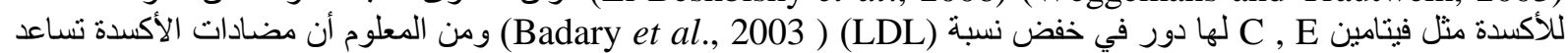

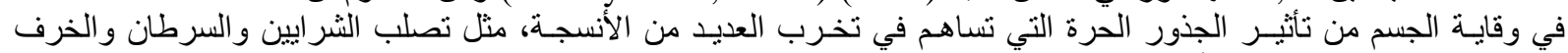

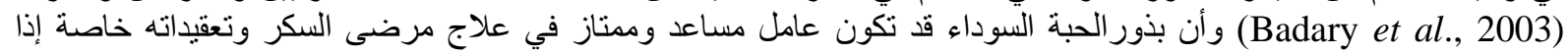
استعمل لفترة طويلة (Ayed and Talal., 2011)

أما بالنسبة للحلبة فإن مناقثة مستوى (LDL) متر ابطة مع ماتم ذكره في مناقثتة الكولسترول و الثحوم الثالاثية في مصل الدم .

خامساً- تأثير الخلاصة الميثانولية لبذور (الحبة السوداء، الحلبة) على مستوى نسبة الليبوبروتينات عالية الكثافة (HDL) في مصل الدم: Effect of of methalonic extract of Fenugreek and Nigella Sativa seeds on serum high - density lipoproteins blood level

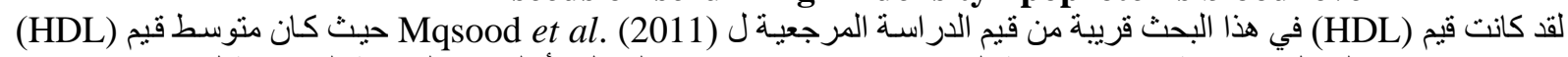

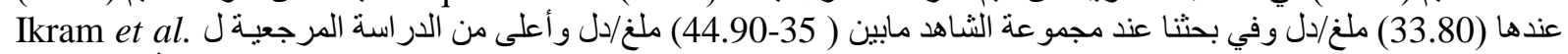

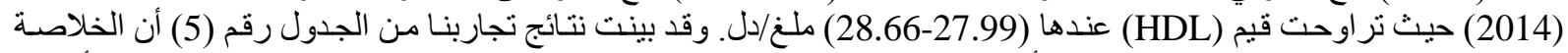

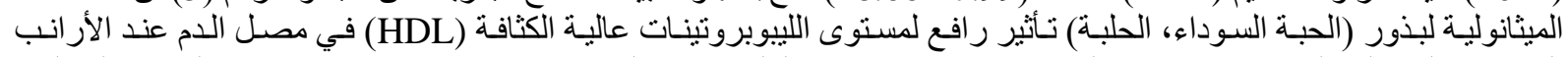

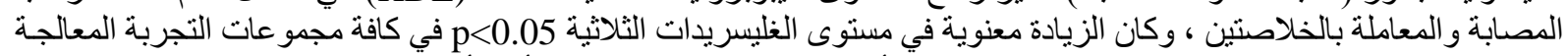

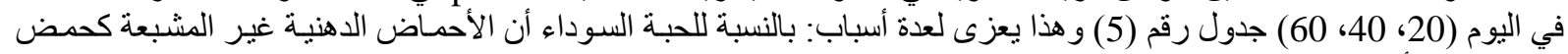

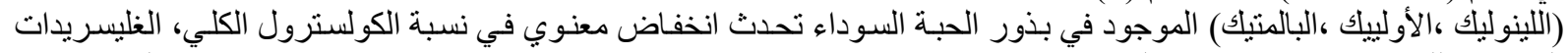

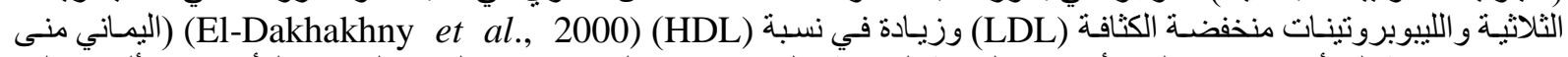

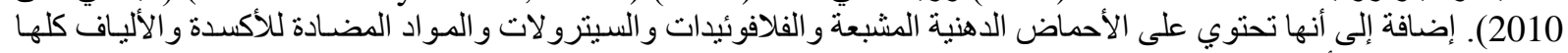

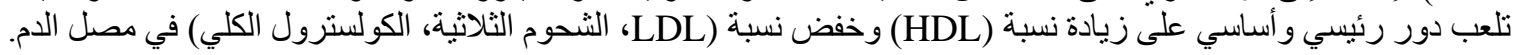
.(Feldman, 2001)، (Abdel-Aal and attia, 1993)، (Gad et al., 1963)

أما بالنسبة للحلبة فإن مناقتة (HDL) مثر ابطة مع ماتم ذكره في مناقثنة الكولسترول و الثحوم الثلاثثة و(LDL) في مصل الدم حيث

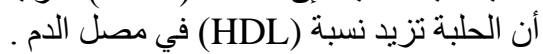

\section{CONCLUSIONS}

\section{الاستنتاجـات}

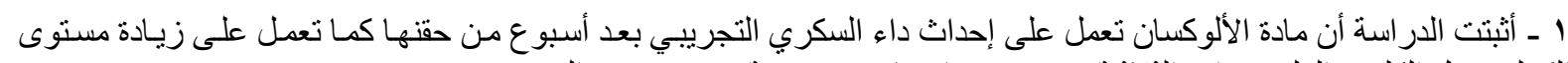

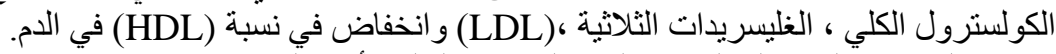

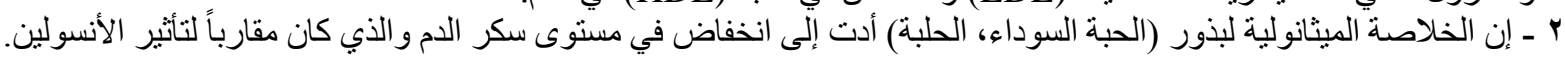

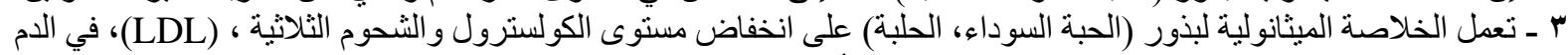

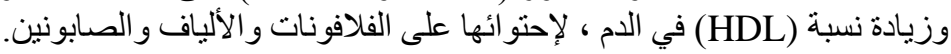

\section{RECOMMENDATION \\ التوصيـات}

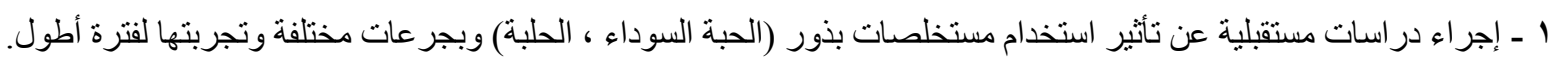

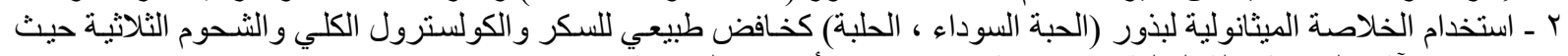

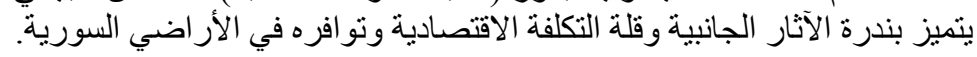




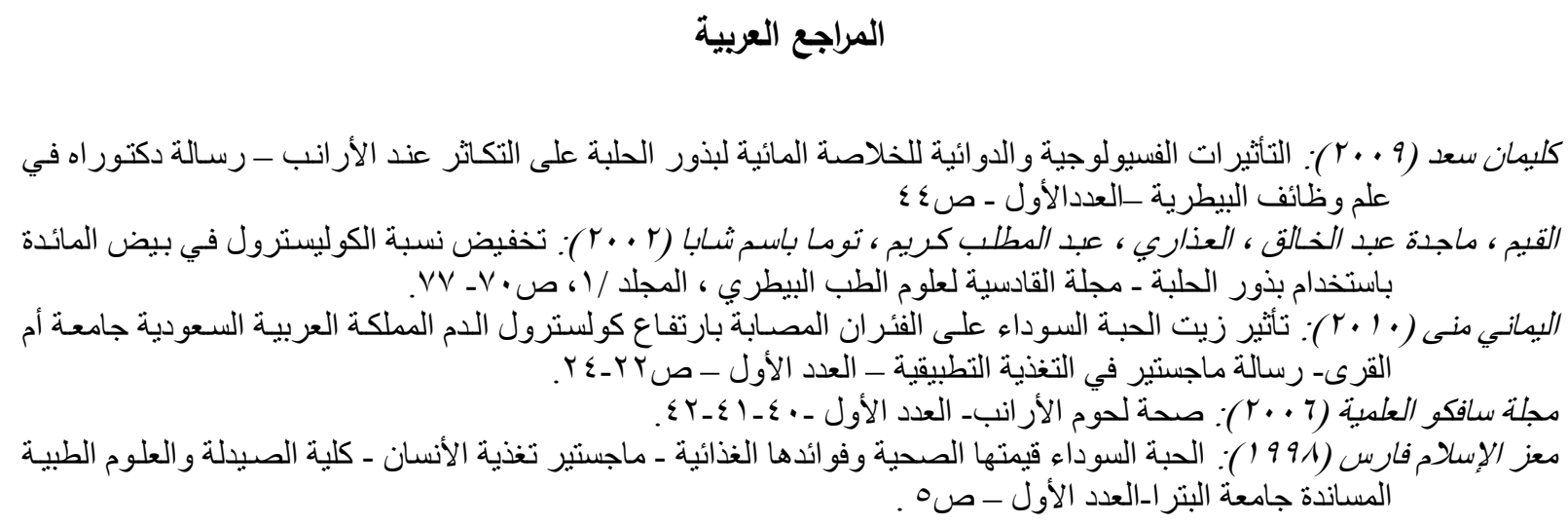

\section{REFERENCES}

المراجع الأجنبية

Abdel-Aal, E.S. and Attia, R.S. (1993): Characterization of black cumin (Nigella sativa) seeds Alexandria I Science Exchange, 14, 483-496.

Abdel-Barry, J.A. and AL-Hakiem, M.H. (2000): Acute intraperrtoneal and oral toxicity of the leaf glycosidic extract of Trigonella foenum gracum in mice. J. Ethnopharmacol. 70(1): 65-8.

Abdelmeguid, NE.; Fakhoury, R.; Kamal, SM. and Al Wafai, R.J. (2010): Effects of Nigella sativa and thymoquinone on biochemical and subcellular changes in pancreatic $\beta$-cells of streptozotocininduced diabetic rats. J. Diabetes; 2: 256-66.

AL-Habori, M.; Raman, A.; Lawrence, M.J. and SKett, P. (2001): In vitro effect of fenugreek extracts on intestinal sodium-dependent glucose uptake and hepatic glycogen phosphorylase A. Int. J. Exp. Diabetes Res.2(2): 91-9.

Aloulou, A.; Hamden, K.; Elloumi, D.; Ali, MB.; Hargafi, K.; Jaouadi, B.; Ayadi, F.; Elfeki, A. and Ammar, E. (2012): Hypoglycemic and antilipidemic properties of kombucha tea in alloxaninduced diabetic rats. BMC omplement Altern Med. 12: 63. http://dx.doi.org/10.1186/14726882-12-63.

Amein, AL.A.; Abdul, A.; Mohammad, R. and Nisar, SH. (2008): Oral and intraperitoneal LD50 of Thymoquinone., An Active principle of Nigella Sativa, in Mice and Rats. 2-20.

Analava Mitra and Debaprased Bhattacharya. (2006): Dose-dependent effects of Fenugreek composite in Diabetes with dislipidaema. Internet Journal of Food Safety. Vol.8: p49-55.

Ananthan, R.; Latha, M.; Ramakumar, K.M.; Pari, L. and Narmatha, B. (2003): Effect of Gymnema montanum leaves on serum and tissue lipids in alloxan diabetic rats, 4:183-189. Alloxannduced Diabetic Rabbits (Oryctolagus cuniculus) ISSN: 0253-8318 (PRINT), 2074-7764 (ONLINE).

Arts, IC. and Hollman, PC. (2005): Polyphenols and disease risk in epidemiologic studies. Am. J. Clin. Nutr. 81: 317S-325S.

Ayed, Al, Talal. (2011): Long-term effects of Nigella sativa L. oil on some physiological parameters in normal and streptozotocin-induced diabetic rats Vol.1, No.3, 46-53.

Badary, O.A.; Taha, R.A.; Gamalel-Din, A.M. and Ab-del-Wahab, M.H. (2003): Thymoquinone is a potent su-peroxide anion scavenger.Drug.Chemi 26, 87-98. doi: 10.1081DCT-120020404.

Bahram., P-Gargari1, V.; Ebrahimzadeh., A. Maryam. and Abolfazl., G. (2009): Effect of dietary supplementation withNigella sativa L. on serum lipid profile, lipid peroxidation and antioxidant defense system in hyperlipidemic rabbits Journal of Medicinal Plants esearch Vol. 3(10), pp. 815-821, OctoberISSN 1996-0875 Academic Journals.

Balaha, MF.; Tanaka, H.; Yamashita, H.; Abdel Rahman, MN. and Inagaki, N. (2012): Oral Nigella sativa oil ameliorates ovalbumin-induced bronchial asthma in mice. Int Immunopharmacol $14: 224-31$. 
Bamosa, AO.; Kaatabi, H.; Lebdaa, FM.; Elq, AM. and Al-Sultan, A. (2010): Effect of Nigella sativa seeds on the glycemic control of patients with type2 diabetes mellitus. Indian J. Physiol Pharmacol; 54: 344-54.

Benhaddou-Andaloussi, A. and Elimadi, A. (2004): The petroleum ether extract of Nigella sativa exerts lipid-lowering and insulin- sensitizing actions in the rat.J Ethnopharmacol; 94:251-9.

Blumenthal, M.; Goldberg, A. and Brinckmann, J. (2000): Herbale Medicine: Expanded Commission E Monographs Copyright American Botanical Council. Publ. by Integrative Medicine Communications, 1029 Chestnut Street, Newton MA02464Pp.130-133.

Cara., L.; Dobis, C.; Borel, P.; Armand, M.; Senft, M.; Portugal, H.; Pauli, AM.; Bernard, P.M. and Lairon, D. (1992): Effects of oat bran. rice bran, wheat fiber, and wheatgerm on postprandial Lipidemia in health adulte. Am. J. Clin.Nutr. 55: 81-88.

Daniel, Z. and Maria, H. (2000): Domestication of plants in the Old World, Black Seed Botanical and Historical Information: third edition (Oxford: University Press, pag. 206.

Deshmuk, S. and Borle, M. (1975): Studies on the insecticidal properties of indigenous plant products. G. Ethropharmacol., 37: 11-18.

Dey, L.; Attele, AS. And Yuan, C-S. (2002): Alternative therapies for type2 diabeetes. Altern Med Rev.7: 45-58

El-Beshbishy, HA.; Singab, ANB.; Sinkkonen, J. and Pihlaja, K. (2006): Hypolipidemic and antioxidant effects of Morus alba L. (Egyptian mulberry) root bark fractions supplementation in cholesterol-fed rats. Life Sci. 78: 2724-2733.

El-Dakhakhny, M.; Barakat, M. Abdel. and El-Halim M, Aly SM. (2000): Effects of Nigella sativa oil on gastric secretion and ethanol-induced ulcer in rats. J Ethnopharmacol 72: 299-304.

Feldman, E.B. (2001): Cardiovascular disease prevention by diet. In: Berdanier, C.D., Ed., CRC Han trit ion and Foods, CRC Press, Boca Raton.

Hannana, J.M.A.; Rokeya, B. and Faruque, O. (2003): Effect of soluble dietary fibre fraction Trigonella foenum graecum on glycemic, insuinemic lipidemic and platelet aggregation status of type 2 diabetic model rats. J. Ethnopharmacol., 88: 73-77.

Gad, A.M.; El-Dakhakhny, M. and Hassan, M.M. (1963): Studies on the chemical composition of Egypsativa L. oil. Planta Medica, 11, 134-138. Doi: 10.1111/j.1365-2621.1978.tb15297.x .

Harvey, L.; Arnold, B.; Lawrence, Z.S.; Paul, M.; David, B. and James, D.E. (1999): Molecular Cell Biology,4th .ed. New York. W.H. Freeman and Co. U.S.A.

Heafele, C.; Bonfils, C. and Sauvaire, Y. (1997): Characterization of a dioxygenase from Trigonella foenum- graecum involved in 4- hydroxyl isoleucine biosynthesis Photochemistry, 44 (4): 563. (Abstract).

Ikram Fa, Hussain Fb. (2014): Antidiabetic Efficacy of Nigella sativa inn. In Alloxan-induced Diabetic Rabbits THE INTERNATIONAL MEDICAL JOURNAL Malaysia Volume 13 Number 1.

Kanter, M.; Meral, I.; Yener, Z.; Ozber, H. and Demir, H. (2003): Partial regeneration/proliferation of the-cells in the islets of Langerhand by Nigella sativa L. in streptozotocin-induced diabetic rats. Tohoku J. Exp Med.201:213-9.

Katsumata, K. and Katsumata, Y. (1990): The potentiating effect of the simultaneous administration of tolbutamide, glibenclamide, and gliclazide on the development of alloxan - induced diabetes in rats .Hom. Metab. Res., 22: 51-52.

Khaled, H.; Kais, M.; Zahra, A.; Ahmed, A. and Abdelfattah, E. (2012): Inhibition of Key Digestive Enzymes Related to Diabetes and Hyperlipidemia and Protection of Liver-Kidney Functions by Trigonelline in Diabetic Rats. Research article m. b.H., Vienna, Austria.

Khosla, P.; Gupta, D.D. and Nagpol, R.K. (1995): Effect of Trigonella foenum - graesum (Fenugreek) on blood glucose in normal and diabetic rats. Indian J. Physiol. Pharmacol. 39.

Langslow, D.R.; Butler, E.J.; Hales, C.N. and Pearson, A.W. (1970): The response of plasma insulin, glucose and non-esterifies fatty acids to various hormones, nutrients and drugs in the domestic fowl. J. Endocrinol.46:243.

Madar, Z.; Abel, R.; Samish, S. and Arad, J. (1988): Glucoselowering effect of fenugreek in noninsulindependent diabetics. Eur J Clin Nutr; 42: 51-54.

Maqsood, A.; Qaisar, M.; Kamran, G.; Muhammad, S.A; Mohammad Saleem and Muhammad IQ. (2011): Antihyperlipidemic and Hepatoprotective Activity of Dodonaea viscosa Leaves Extracts 
in Alloxan-Induced Diabetic Rabbits (Oryctolagus cuniculus) ISSN: 0253-8318 (PRINT), 20747764.

Meral, I.; Yener, Z.; Kahraman, T. and Mert, N. (2001): Effect of Nigella sativa on glucose concentration, lipid peroxidation, antioxidant defence system and liver damage in experimentally induced diabetic rabbits. J. Vet. Med. Physiol. Pathol. Clin. Med. 48 (10): 5939.

Moyers, SB. and Kumar, NB. (2004): Green tea polyphenols and cancer chemoprevention: multiple mechanisms and endpoints for phase trials. Nutr. Rev. 62 (5): 204-211.

Natarajan, B. and Dhananjayan, R. (2007): Pharmacological effects of Trigonella foenum graecum seeds on various isolated perfused smooth muscle preparations.phcog Mag.Vol3: Issue 10, AprJun.77.

Nussey, S. and Whitehead, S.A. (2001): Endocrincology: An Intergrated Approach. Bios. Scientific Publishers. Ltd. Oxford, U.K

Rchid H, Chevassus H, Nmila R, (2004): Nigella sativa seed extracts enhance glucose-induced 18 insulin release from rat-isolated Langerhans islets. Fundam Clin Pharmacol; 18:525-9.

Sauvaire, Y.; Ribes, G.; Baccou, JC. and Loubatieres-Mariani, MM. (1991): Implication of steroid saponins and sapogenins in the hypocholesterolaemic effect of fenugreek. Lipids; 26: 191-7.

Sharma, RD.; Raghuram, TC. and Rao, VD. (1991): Hypolipidaemic effect of fenugreek seeds. A clinical study. Phytother Res 5:145-147.

Sowmya, R. and Rajyalakshmi, R. (1999): Hypocholesterolemic effect of germinated fenugreek seeds in human subjects. Plant Foods Hum Nutr 53: 359-365.

Stark, A. and Madar, Z. (1993): The effect of an ethanol extract derived from from fenugreek (Trigonella foenum- graacum) on bile acid absorption and cholesterol levels in rats. Br J Nutr. 69: 277-287.

(ANOVA One way. Newman Keuls vers 8) (2008): (Statistica USA Story JA, Kelley MJ. Dietary fibre and lipoproteins. (1982): In The effect of dietary fibre on lipoprotein cholesterol is due to its association with absorption and transport of lipids Dietary Fiber in Health Disease. G.V. Vahouny and D. Kritchevsky pp 229-36. (Eds.) Plenum Press, New York.

Subash, B.P.; Prabuseenivasan, S. and Ignacimuthu, S. (2006): Cinnamaldehyde-Apotential antidiabetic agent. Phytomedicine, 14,15-22. doi:10.1016/j.phymed. 11.005.

Taba, D.; Nicula, M.; Morara, D.; Bura, M.; Dronca and ilion, S. (2008): Comparative researche regarding metabolic profile of the Calefornia, New Zealand white,Grand Chinchilla meat rabbit breeds and he f1 Nzch Hybrids. J. Biotecnology., 41:2.

Townsend, C.C. and Guest, E. (1980): Flora of raq.Vol.4 (part1) Ministry of Agriculture and Agrarian reform. Baghdad. pp. 495.

Sher, G. (1984): A Dictionary of Plants U sed by Man. CBS publishers and Distributors. Delhi. pp465.

Usher, G. (1984): A Dictionary of Plants U sed by Man. CBS publishers and Distributors. Delhi. pp465.

Vladova, AM. Stefanov and Y. Toneva. Bulgarian Journal of Veterinary Medicine. (2005): Changes in blood glucose, Triglycerides and lipid peroxidation products in rabbits after hangingfixation, 8 , No3.

Weggemans, RM. and Trautwein, EA. (2003): Relation between soyassociated isoflavones and LDL and HDL cholesterol concentrations in humans: a Meta analyses. Eur. J. Clin. Nutr. 57 (8): 940 946.

Xue, W.; Li, X.; Zhang, J.; Liu, Y.; Wang, Zh. and Zhang, RJ. (2007): Effect of Trigonella foenumgraecum (fenugreek) extract on blood glucose, blood lipid and hemorheological properties in streptozotocin-induced diabetic rats. Asi. Pak J. Clin Nutr, 16 (Suppl 1): 422-426. 